\title{
Water Kefir and Derived Pasteurized Beverages Modulate Gut Microbiota, Intestinal Permeability and Cytokine Production In Vitro
}

\author{
Marta Calatayud ${ }^{1,2,+}$, Rosa Aragao Börner ${ }^{3, *,+}{ }^{(D)}$, Jonas Ghyselinck ${ }^{1}$, Lynn Verstrepen ${ }^{1}$, Jelle De Medts ${ }^{1}$, \\ Pieter Van den Abbeele ${ }^{1}$, Claire L. Boulangé ${ }^{3}$, Sarah Priour ${ }^{3}$, Massimo Marzorati ${ }^{1,2, *}$ and Sami Damak $^{3}$
}

1 ProDigest, Technologiepark 82, 9052 Zwijnaarde, Belgium; Marta.Calatayud@prodigest.eu (M.C.); Jonas.Ghyselinck@prodigest.eu (J.G.); Lynn.Verstrepen@prodigest.eu (L.V.); Jelle.DeMedts@prodigest.eu (J.D.M.); Pieter.VandenAbbeele@telenet.be (P.V.d.A.)

2 Center for Microbial Ecology and Technology (CMET), Faculty of Bioscience Engineering, Ghent University, Coupure Links 653, 9000 Ghent, Belgium

3 Nestlé Institute of Health Sciences, and Nestlé Institute of Material Sciences, Nestlé Research, Société des Produits Nestlé S.A., Vers-chez-les-Blanc, 1000 Lausanne, Switzerland; claire.boulange@rd.nestle.com (C.L.B.); Sarah.Priour@rd.nestle.com (S.P.); sami.damak@rdls.nestle.com (S.D.)

* Correspondence: Rosa.AragaoBoerner@rd.nestle.com (R.A.B.); Massimo.marzorati@prodigest.eu (M.M.)

+ These authors contributed equally to this work.

Citation: Calatayud, M.; Börner, R.A.; Ghyselinck, J.; Verstrepen, L.; Medts, J.D.; Abbeele, P.V.d.; Boulangé, C.L.; Priour, S.; Marzorati, M.; Damak,

S. Water Kefir and Derived

Pasteurized Beverages Modulate Gut Microbiota, Intestinal Permeability and Cytokine Production In Vitro. Nutrients 2021, 13, 3897. https:// doi.org/10.3390/nu13113897

Academic Editor: Patrick R.M. Lauwers

Received: 21 September 2021

Accepted: 27 October 2021

Published: 29 October 2021

Publisher's Note: MDPI stays neutral with regard to jurisdictional claims in published maps and institutional affiliations.

Copyright: (c) 2021 by the authors. Licensee MDPI, Basel, Switzerland. This article is an open access article distributed under the terms and conditions of the Creative Commons Attribution (CC BY) license (https:// creativecommons.org/licenses/by/ $4.0 /)$

\begin{abstract}
Fermentation is an ancient food preservation process, and fermented products have been traditionally consumed in different cultures worldwide over the years. The interplay between human gut microbiota, diet and host health is widely recognized. Diet is one of the main factors modulating gut microbiota potentially with beneficial effects on human health. Fermented dairy products have received much attention, but other sources of probiotic delivery through food received far less attention. In this research, a combination of in vitro tools mimicking colonic fermentation and the intestinal epithelium have been applied to study the effect of different pasteurized and non-pasteurized water kefir products on gut microbiota, epithelial barrier function and immunomodulation. Water kefir increased beneficial short-chain fatty acid production at the microbial level, reduced detrimental proteolytic fermentation compounds and increased Bifidobacterium genus abundance. The observed benefits are enhanced by pasteurization. Pasteurized products also had a significant effect at the host level, improving inflammation-induced intestinal epithelial barrier disruption and increasing IL-10 and IL-1 $\beta$ compared to the control condition. Our data support the potential health benefits of water kefir and demonstrate that pasteurization, performed to prolong shelf life and stability of the product, also enhanced these benefits.
\end{abstract}

Keywords: water kefir; microbiota; immunomodulation; short-chain fatty acids; gut barrier

\section{Introduction}

Gut microbes play a key role in human health, including the development of the immune system [1-3] and host metabolism [4,5]. In addition, several studies have shown associations between changes in the gut microbiota and various diseases including allergy [6], inflammatory bowel disease [7], diabetes [8,9], asthma [10,11], and obesity [12].

Fermented products have been linked to health benefits, potentially through gut microbiota modulation. Indeed, fermented products can be considered a source of probiotic microorganisms, defined as live microorganisms that confer a health benefit on the host [13].

Among fermented food products, water kefir, is made by fermentation of simple carbohydrate solutions (e.g., sucrose, glucose, fructose) and dried fruits like figs or dates, generating a beverage with a blond to yellowish color, acidic and slightly alcoholic [14]. The origin of water-kefir is not fully clear, with some descriptions of similar grains reported at the end of the XIX century in Europe coming from the Crimea but there are also reports 
of sources in Mexico [15]. The fermentations are typically performed at household level and grains are traditionally passed hand in hand [16].

Similar to milk kefir, the fermentation of water kefir is carried out by a distinct starter cultures attached to predominantly polysaccharide matrix called the kefir grain or tibicos. However, differently to milk kefir, the polysaccharide matrix is mostly composed of dextran produced by a variety of lactic acid bacteria species $[17,18]$. These are comprised mostly of a consortium of lactic acid bacteria, acetic acid bacteria and yeast $[14,16,18,19]$. Though, clear distinctions to milk kefir are observed in the composition and microbial populations due to the different carbon and energy source for the fermentation $[15,18,20,21]$, which results in variations of the final fermented product. The fermentation of water kefir results in cell growth and associated polysaccharide formation, organic acids, alcohols, carbon dioxide and aroma compounds that are characteristic to the product [17].

Multiple potential health-benefits have been associated with milk kefir, mainly derived from in vitro and animal studies. These effects include immunomodulatory, cholesterollowering, anti-allergic, anti-inflammatory, antitumoral, antimicrobial activity (reviewed in [22]) and effect on the gut microbiota to modulate brain physiology [23], linked to the microbial composition of the fermented product, but also to the presence of bioactive molecules and kefiran [21,23]. Most of the current literature evaluating health effects associated to kefir consumption refers to dairy products, but non-dairy kefir derivatives were also linked to specific bioactivity including anti-inflammatory, antiulcerogenic, antihyperglycemic and antihyperlipidemic potential in rodent models (reviewed in [24]). Considering a relative resemblance in consortia composition and microbial dynamics during the fermentation of milk and water kefir, certain similarities could potentially be expected, however due to the main different in substrate, their potential benefit effect should be verified.

Potential health benefits for dairy and non-dairy kefir are mainly related to specific bioactivity of product components or activities of isolates (reviewed in [25]). For example, antimicrobial activity of kefir derived bioactives originated from sugar-broth fermentation have been demonstrated against Candida albicans, Salmonella typhi, Shigella sonnei, Staphylococcus aureus and Escherichia coli [26]. Rocha-Gomes et al., 2018 showed that supplemented rats with water kefir had an improved plasma and hepatic lipid profile in comparison to the control [27], whereas streptozotocin-induced diabetic rats treated with water kefir showed an improvement in body weight, glucose, and lipid profiles compared with diabetic rats [28]. Water kefir was also proved to be effective in promoting hepatoprotection in a rat model of acetaminophen-induced toxicity, decreasing levels of liver enzymes [29]. Specific lactobacilli strains isolated from Malaysian Kefir and propagated in brown sugar solutions showed high survival to low (3-4) $\mathrm{pH}$, antioxidant properties and high adherence to intestinal cells [30]. However, most of the current literature assessing beneficial properties of kefir is primarily based on in vitro or animal tests, or makes use of dairy kefir products, so further clinical trials are needed to comprehensively assess the effect of water kefir consumption on specific health parameters in healthy and/or diseases population groups. Some commercial kefirs have more complex, less defined culture mixtures, and the mixes differ depending on the source and geographical origin [18]. Pasteurization is a commonly used process on industrial beverages to maintain its safety and organoleptic properties during shelf life. The roles of the microbiota and of pasteurization in mediating the benefits of water kefir have not been clarified. Therefore, further characterization of commercial kefir products on human microbiota and host-microbiome interplay and the effect of pasteurization are still required.

This study assessed in vitro the effect of two water kefir fermented products, a nonpasteurized and a pasteurized form, on microbial metabolic activity and community composition in an in-vitro gastrointestinal system, using short-term colonic incubations representative of three healthy donors. The protective effect of microbial fermentation products derived from the interaction between kefir and gut microbiota on inflammationinduced intestinal epithelial barrier disruption and cytokine production was further evalu- 
ated in a co-culture of intestinal epithelial and macrophage-like cells. Incorporating human interindividual variability, microbiota-microbiota and host-microbiota interplay along with pasteurized products representing paraprobiotics (non-viable probiotics) and postbiotics (metabolites and/or cell wall components released by probiotics) in tightly controlled in vitro conditions, provides a better understanding of the potential effects of water kefir on human gut microbiota and intestinal function.

\section{Materials and Methods}

\subsection{Test Products}

All chemicals were obtained from Merck (Darmstadt, Germany) unless stated otherwise. The products tested in this research were obtained from Nestlé and consisted of fermented beverages (water kefir) made with two starter cultures.

Water kefir products were prepared in lab scale simulating home-based products. The grains were obtained from two different sources. Grains referred as K1 were obtained from a household source in Lausanne, Switzerland. The second starter culture were commercial dried water kefir grains obtained from Culture for Health, LLC, Akron, OH, USA. The microbial composition in terms of culturable aerobic mesophilic bacteria, acid lactic bacteria and yeasts of the two kefir cultures is described in Supplementary Table S1. Initially, grains were activated by sub-culturing them twice, in a sugar water supplemented with fig extract: $10.7 \%(w / w)$ of grains and $8.8 \%(w / w)$ of backslope was added to $78.8 \%(w / w)$ of cane sugar solution and $0.5 \%(w / v)$ fig extract, then left at room temperature for 2 to 3 days. Sucrose solution was generated consisting $5 \%(w / w)$ of cane sugar (Migros, Zürich, Switzerland) in two different mineral waters, (V) or $(\mathrm{H})$ (Nestlé, Vevey, Switzerland) filtered through a $0.2 \mu \mathrm{m}$ sterile filter. Fig (fruit) extract consisted in a $25 \%(w / v)$ of dried figs (Migros, Switzerland), homogenized mineral water, using an Ultra-Turrax (IKA, Staufen, Germany) then centrifuged $7200 \times g$ for $20 \mathrm{~min}$ (SORVALL RC6+ Thermo Scientific, Waltham, MA, USA). The supernatant was collected and autoclaved $\left(121^{\circ} \mathrm{C}\right.$ for $15 \mathrm{~min}$; GETINGE GEV6613) before use. For the kefir production, 10.7\% $(w / w)$ of grains were added to a freshly prepared sucrose solution together with $8.8 \%(w / w)$ of backslope, i.e., liquid media resulting from the sub-culture of the kefir grains. Fermentation was carried out in two phases. First, water kefirs were incubated for $24 \mathrm{~h}$ at $30^{\circ} \mathrm{C}$ in a glass jar covered with a coffee filter. Second, grains were sieved out using a sieve with $1 \mathrm{~mm}$ pores and $0.66 \%(w / w)$ of blueberry juice concentrate (Döhler, Germany) plus $0.74 \%$ of raspberry juice concentrate (Döhler, Germany) were added to the resulting water kefir liquor. Bottles were closed and left for a second fermentation at $30^{\circ} \mathrm{C}$ for 6 additional hours. At the end of the fermentation samples were pasteurized in a steam oven, at $72{ }^{\circ} \mathrm{C}$ for $3 \mathrm{~min}$, and directly put on ice.

The composition of the different products was analyzed by HPLC coupled with a refractive index and UV detector (HPLC RI/UV, Agilent Technologies AG, Basel, Switzerland) using the Aminex 87H column (BioRad, Hercules, CA, USA), including total sugars, sucrose, fructose, glucose, ethanol and glucuronic, citric, lactic and acetic acids. $20 \mu \mathrm{L}$ of injected volume were separated isocratically with $5 \mathrm{mM} \mathrm{H}_{2} \mathrm{SO}_{4}$ for 45 min with a flow rate of $0.6 \mathrm{~mL} / \mathrm{min}$ and column temperature of $35^{\circ} \mathrm{C}$. Peaks were integrated and quantified using external standards for each specific compound (Merk-Sigma Aldrich, Burlington, MA, USA) via ChemStation (Agilent Technologies). Glucuronic acid, glycerol, propionic acid and butyric acid were also measured but were below the limit of quantification. Aaerobic mesophilic bacteria (AMB), lactic acid bacteria (LAB) and yeast were quantified as described in Supplementary Table S2.

\subsection{Fecal Sample Collection and Donor Description}

Human healthy donors $(n=3)$ were selected based on the following inclusion criteria: healthy, aged between 18-45 years, no antibiotic or any other drug intake during the last 6 months, no constipation, no pre-or probiotic intake. Samples were obtained in special 
containers containing an "Oxoid ${ }^{\mathrm{TM}}$ AnaeroGen" ${ }^{\mathrm{TM}}$ " bag to limit the sample's exposure to oxygen. Samples were immediately transferred to the lab for further use.

\subsection{Experimental Design of Short-Term Incubations}

A short-term batch assay was performed to assess the effect of a single dose of fermented beverages on the gut microbiota composition and activity of three healthy adults (Figure 1).

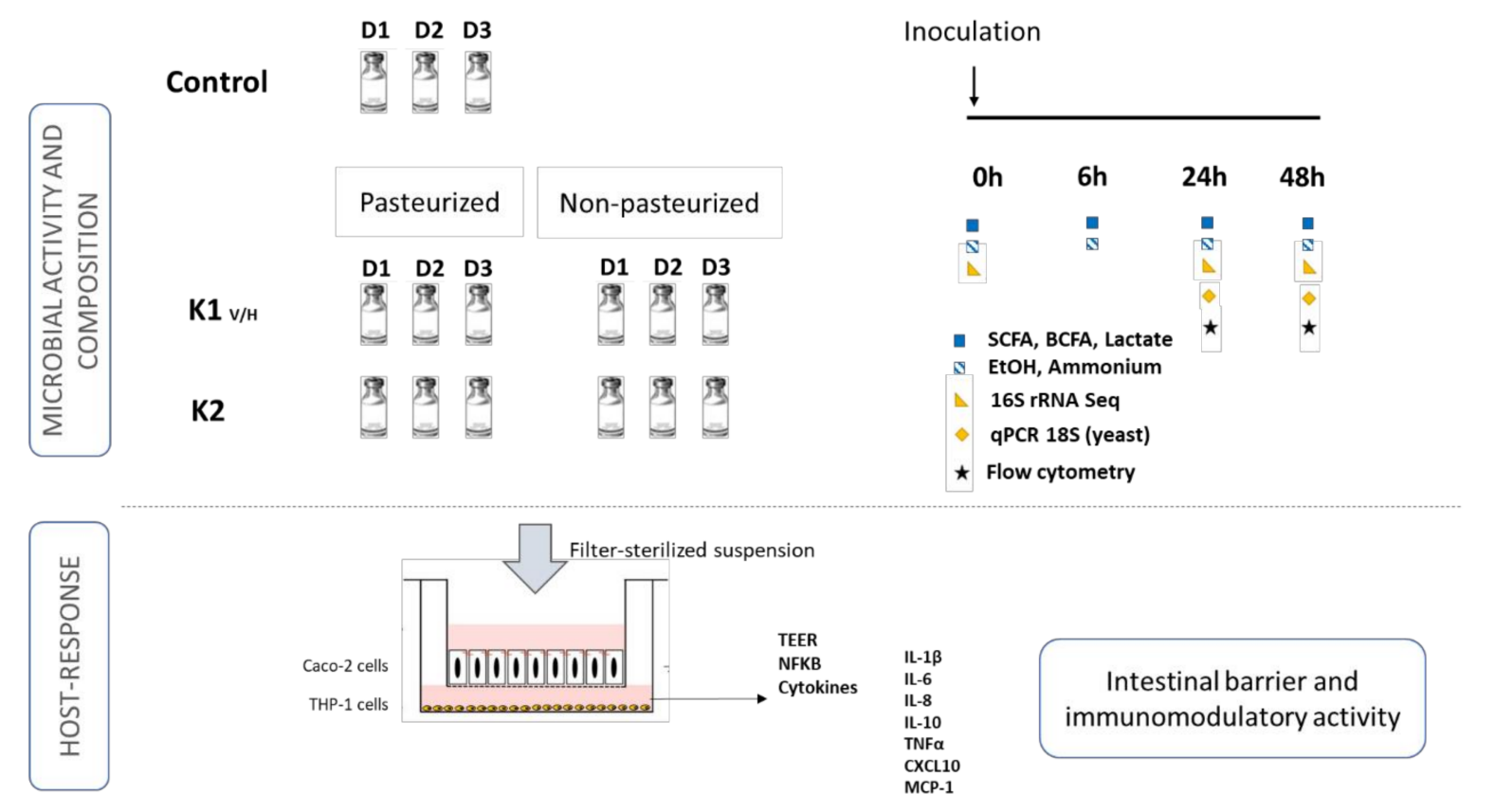

Figure 1. Schematic representation of the experimental set up. SFCA = short-chain fatty acid; BCFA = branched-chain fatty acid; $\mathrm{EtOH}=$ ethanol; TEER = transepithelial electrical resistance. $\mathrm{D}=$ donor; $\mathrm{K}=$ kefir.

Short-term incubations were performed as previously described [31]. Briefly, $57.4 \mathrm{~mL}$ of colonic background medium $\left(\mathrm{K}_{2} \mathrm{HPO}_{4} 5.7 \mathrm{~g} / \mathrm{L} ; \mathrm{KH}_{2} \mathrm{PO}_{4} 17.9 \mathrm{~g} / \mathrm{L} ; \mathrm{NaHCO}_{3} ; 2.2 \mathrm{~g} / \mathrm{L}\right.$; yeast extract $2.2 \mathrm{~g} / \mathrm{L}$; peptone $2.2 \mathrm{~g} / \mathrm{L}$; mucin $1.1 \mathrm{~g} / \mathrm{L}$; cysteine $0.5 \mathrm{~g} / \mathrm{L}$; Tween $802.2 \mathrm{~mL} / \mathrm{L}$ ) was mixed with $5.6 \mathrm{~mL}$ of different products, resulting in a dose of nutritional components present in products as described in Supplementary Table S2. A control condition containing colonic medium was run in parallel and all the conditions were tested in single reactors, considering the three donors as biological replicates. Then, the reactors were sealed and anaerobiosis was obtained by continuous flushing of the medium with N2 for $10 \mathrm{~min}$. Subsequently, freshly collected fecal sample from three healthy adults were homogenized in anaerobic phosphate buffer $\left(\mathrm{K}_{2} \mathrm{HPO}_{4} 8.8 \mathrm{~g} / \mathrm{L} ; \mathrm{KH}_{2} \mathrm{PO}_{4} 6.8 \mathrm{~g} / \mathrm{L}\right.$; sodium thioglycolate $0.1 \mathrm{~g} / \mathrm{L}$; sodium dithionite $0.015 \mathrm{~g} / \mathrm{L})$ in a proportion of $7.5 \%(w / v)$ and $7 \mathrm{~mL}$ of the fecal suspension was inoculated in the reactors containing colonic medium with different products.

Samples were collected at $0 \mathrm{~h}, 6 \mathrm{~h}, 24 \mathrm{~h}$ and $48 \mathrm{~h}$ for microbial metabolic activity analysis [ $\mathrm{pH}$, gas production, ammonia, short-chain fatty acids (SCFAs) including acetate, butyrate and propionate, branched-chain fatty acid (BCFA), lactate and ethanol] and at $0 \mathrm{~h}$, $24 \mathrm{~h}$ and $48 \mathrm{~h}$ for community structure analysis (bacterial 16S RNA Illumina sequencing and 18S RNA targeted for total yeasts).

\subsection{DNA Extraction and Microbial Community Analysis}

The DNA was extracted from a pellet of bacterial cells originated from a $1 \mathrm{~mL}$ sample after centrifugation for $5 \mathrm{~min}$ at $7700 \times \mathrm{g}$. A Fastprep-24 device (MP BioMedicals, Illkirch, France) was used for homogenization (two cycles of $40 \mathrm{~s}$ at $4 \mathrm{~m} / \mathrm{s}$ ). Quality control PCR 
was conducted using Taq DNA Polymerase with the Fermentas PCR Kit according to the manufacturers' instructions (Thermo Fisher Scientific, Waltham, MA, USA). The DNA quality was verified by electrophoresis on a $2 \%(w / v)$ agarose gel for $30 \mathrm{~min}$ at $100 \mathrm{~V}$.

Microbial community composition was assessed at the start of the experiment and at 24 and $48 \mathrm{~h}$ of incubation. Samples were sent out to LGC Genomics GmbH (Berlin, Germany) for next-generation 16S rRNA gene amplicon sequencing of the V3-V4 region. Library preparation and sequencing were performed using an Illumina MiSeq platform with v3 chemistry. The 341F (5'-CCTACGGGNGGCWGCAG-3') and 785R (5'-GACTACHVGGGTATCTAAKCC-3') primers were used as previously described [32] with the reverse primer being adapted to increase coverage.

Subsequently, the qPCR for total yeast quantification were performed using a QuantStudio 5 Real-Time PCR system (Applied Biosystems, Foster City, CA, USA), using the primers and conditions described in Supplementary Tables S3 and S4, adapted from [33]. As standard, samples from a pure culture of Saccharomyces cerevisiae strain ySR128 was included. The standard curves for all runs had efficiencies between 90 and 105\%. Samples were analyzed in technical triplicates and melt curve peaks were checked in each run. Results are reported as log units (18S rRNA gene copies $/ \mathrm{mL}$ ).

\subsection{Quantification of Total Bacterial Cells by Flow Cytometry}

Bacterial cell densities were measured using a BD FacsVerse flow cytometer and live cells were distinguished from damaged cells using SYBR Green (SG; Thermo Fisher, Merelbeke, Belgium)/propidium iodide (PI;Merck KGaA, Darmstadt, Germany) staining, as previously described [34]. Proportional values obtained with Illumina sequencing were converted into absolute quantities by correcting with live bacterial cell counts. Bacterial cells were separated from medium debris and signal noise by applying a threshold level of 200 on the SYTO channel.

\subsection{Metabolic Analysis}

Metabolic parameters were quantified at $\mathrm{t} 0, \mathrm{t} 24$ and $\mathrm{t} 48$. In addition, lactate was measured at $6 \mathrm{~h}(\mathrm{t} 6)$. $\mathrm{pH}$ measurements were performed using a Senseline $\mathrm{pH}$ meter F410 (ProSense, Oosterhout, The Netherlands). Gas formation was measured using a pressure meter to which a needle was connected (Hand-held pressure indicator CPH6200; Wika, Echt, The Netherlands). Gas phase composition was analyzed using a compact GC (Global Analyser Solutions, Breda, The Netherlands), equipped with a Molsieve 5A pre-column and Porabond column (for $\mathrm{CH}_{4}, \mathrm{O}_{2}, \mathrm{H}_{2}, \mathrm{~N}_{2}$ ), a Rt-Q-bond pre-column and column (for $\mathrm{CO}_{2}, \mathrm{~N}_{2} \mathrm{O}$ and $\mathrm{H}_{2} \mathrm{~S}$ ), and a thermal conductivity detector. SCFA (acetate, propionate, and butyrate) and BCFA (isobutyrate, isovalerate, and isocaproate) were determined as described previously [35]. Lactate production was assessed with a kit (R-Biopharm, Darmstadt, Germany) according to manufacturer's instructions.

\subsection{Cell Culture}

Routine maintenance of cells was performed as described [36]. Briefly, Caco-2 cells (HTB-37; American Type Culture Collection, Manassas, VA, USA) were maintained in Dulbecco's Modified Eagle Medium (DMEM) containing glucose and glutamine and supplemented with HEPES and 20\% $(v / v)$ heat-inactivated (HI) fetal bovine serum (FBS). THP1-Blue ${ }^{\mathrm{TM}}$ were obtained from InvivoGen (Belgium) and consisted in stably transfected cell line with a reporter construct expressing a secreted alkaline phosphatase (SEAP) gene under the control of a promoter inducible by the transcription factor nuclear factor kappa B (NF-kB). THP1-Blue were maintained in Roswell Park Memorial Institute (RPMI)1640 medium containing glucose and glutamine, supplemented with HEPES, sodium pyruvate and $10 \%(v / v)$ HI-FBS. Cells were incubated at $37^{\circ} \mathrm{C}$ in a humidified atmosphere of air $/ \mathrm{CO}_{2}(95: 5, v / v)$.

The Caco-2/THP-1 co-culture was done as previously described [36]. Caco-2 monolayers were differentiated for 14 days on 24-well semi-permeable supports $\left(7.5 \times 10^{4} \mathrm{cells} / \mathrm{cm}^{2}\right)$, 
until a functional cell monolayer with a transepithelial electrical resistance (TEER) above $500 \mathrm{ohm} \Omega \mathrm{cm}^{2}$ was obtained. $48 \mathrm{~h}$ before the start of the co-culture, THP1-Blue ${ }^{\mathrm{TM}}$ cells were seeded in 24-well plates and stimulated for $48 \mathrm{~h}$ with phorbol 12-myristate 13-acetate (PMA) at a concentration of $100 \mathrm{ng} / \mathrm{mL}$ to induce macrophage-like phenotype in THP1 cells [37]. After PMA removal, Caco-2-bearing supports were placed on top of PMA-THP1Blue ${ }^{\mathrm{TM}}$ cells, followed by apical treatment with either complete medium or filter-sterilized $(0.22 \mu \mathrm{m})$ colonic suspensions collected after $24 \mathrm{~h}$ and $48 \mathrm{~h}$ of incubation. All treatments were done in biological triplicate. TEER was assessed at timepoint $0 \mathrm{~h}$ and after $24 \mathrm{~h}$ of co-culturing. After $24 \mathrm{~h}$ of incubation, the basolateral medium was replaced by RMPI supplemented with ultrapure LPS (Escherichia coli K12, InvivoGen, $10 \mathrm{ng} / \mathrm{mL}$ ) to disrupt the barrier or left untreated. After $6 \mathrm{~h}$, basolateral medium was collected for cytokine quantification and NF- $\mathrm{kB}$ activity measurements. Cytokines were measured using the Luminex technology; while secreted embryonic alkaline phosphatase (SEAP) activity was determined by using the QUANTI-Blue reagent (InvivoGen), following manufacturer instructions.

\subsection{Data Analysis}

Bioinformatics analysis of amplicon data was performed as previously described [38]. Briefly, the mothur software package (v.1.33.3) and guidelines were used to process the amplicon data generated by LGC Genomics. In short, after assembling forward and reverse reads, contigs with a length between 441 and 467 bases were aligned to the mothur formatted silva_seed release 119 alignment database, trimmed between positions 6388 and 25316, to be compatible with the $341 \mathrm{~F} / 785 \mathrm{R}$ primers. After removing non-aligning sequences as well as sequences containing homopolymer stretches of more than 12 bases, sequences were pre-clustered allowing up to 4 nucleotide differences. UCHIME was applied to remove chimera. Subsequently, sequences were classified, by means of a naive Bayesian classifier, against the RDP $16 \mathrm{~S}$ rRNA gene training set, version 14 with an 80\% cut-off for the pseudobootstrap confidence score. All sequences that were classified as Eukaryota, Archaea, Chloroplasts and Mitochondria were removed and only bacterial sequences were retained. Also, if sequences could not be classified at all [even at (super)Kingdom level] they were removed. Sequences were binned into Operational Taxonomic Units (OTU's) within each order identified by the preceding classification step. An OTU is defined in this manuscript as a collection of sequences with a length between 402 and 427 nucleotides that are found to be more than $97 \%$ similar to one another in the V3-V4 region of their $16 \mathrm{~S}$ rRNA gene after applying Opticlust clustering [39-42]. Taxonomy was assigned using the RDP version 16 and silva.nr_v123 database $[39,43,44]$. The shared file, containing the number of reads observed for each OTU in each sample, was loaded into Microsoft ${ }^{\circledR \circledast}$ Excel $^{\circledR \circledast} 2016$ MSO (16.0.11901.20070) (Microsoft Corporation, Redmond, WA, USA). Reads occurring only 5 times in all samples were removed, as they were supposedly artefacts or bacteria that were not having any biological impact. For the most abundant OTUs, the sequences retrieved from $3 \%$ dissimilarity level fasta file obtained in mothur were classified through the RDP web interface using the RDP SeqMatch tool. The database search was restricted to type strains with only near-full-length and good quality sequences. The sequences were blasted in NCBI against the 16S rRNA gene sequences, selecting only type material, with optimization of the BLAST algorithm for highly similar sequences (accession date: December 2018) $[39,43,45]$. Although identification to the species level based on short $300 \mathrm{bp}$ reads may involve some ambiguity, the most likely species classification of a few interesting OTUs is reported in the results sections. If two or more species were identified with percentages above $95 \%$, both are presented in the text. In the event of inconsistencies in the results of the RDP SeqMatch tool and NCBI BLAST, no species level classification is provided.

To get a general overview of treatments on microbiota, 16S rRNA raw gene sequences were analyzed using Calypso software Version 8.84. Data were normalized by total sum 
(TSS) and transformed by square root (Hellinger Transformation). Taxa with less than $0.01 \%$ abundance or less than 100 reads were removed.

To take interindividual differences into account, microbial levels at family and OTU for each treatment were normalized by subtracting the value of the control condition for every donor separately. Besides donor effect, the effects of the different treatment parameters were calculated following a similar calculation. In brief, values from pasteurized samples were subtracted from values obtained from non-pasteurized samples per donor to evaluate the pasteurization effect and values from $\mathrm{K} 1$ sample were subtracted from the corresponding K2 sample per donor to assess type of kefir effect. The obtained values for the different conditions were averaged over the three donor and $t$-tests were performed to determine statistical significance between different conditions versus the control.

For each microbial metabolic marker $(\mathrm{pH}$, gas production, SCFA, BCFA, lactate) and qPCR data, changes in production or counts between 0 and $6 \mathrm{~h}(\Delta 6 \mathrm{~h}), 6$ and $24 \mathrm{~h}$ $(\Delta 24 \mathrm{~h})$, and 24 and $48 \mathrm{~h}(\Delta 48 \mathrm{~h})$ were calculated. As each variable showed a different trend on maximum changes depending on time, selected values of maximum differences were used for visual representation. After testing for normality (Shapiro Wilk test), one-way ANOVA test was used to determine significance, with Tukey's multiple comparison test as post-hoc. Arithmetic mean and standard error of the mean (SEM) were used as descriptive statistics. Data were also analyzed after normality test, using two-way ANOVA, including repeated measures on different time points, and checking the interaction between treatment and time. In this case, Dunnett's multiple comparison tests was used to determine the significance between different treatments and the control condition. To compare the overall changes of kefir treatments versus the control, paired $t$-tests were used. A General Linear Model was used to determine the effect of donor, pasteurization, kefir culture and water used for kefir preparation as factors.

Clustvis software was used to perform the Principal Component Analysis (PCA) plots on microbial metabolites. Briefly, unit variance scaling is applied to rows and SVD with imputation was used to calculate principal components, represented in the X (PC1) and Y (PC2) axis. Prediction ellipses were drawn at 95\% of confidence interval.

For cell culture assays, treatment samples were compared to the control samples using two-way ANOVA with Sidak's multiple comparisons test. Significant differences are represented by $\left({ }^{*}\right),\left({ }^{* *}\right),\left({ }^{* * *}\right)$ and $\left({ }^{* * *}\right)$ representing $p<0.05, p<0.01, p<0.001$ and $p<0.0001$, respectively.

Statistical analysis was performed in GraphPad Prism version 8.2.0 (435) for Windows (GraphPad Software, San Diego, CA, USA) or Minitab version 18.1 (Minitab GmbH, Munich, Germany). All formal hypotheses were conducted on the $5 \%$ significance level $(\alpha=0.05)$.

\subsection{Ethics}

Fecal samples of the healthy donors were collected according to the ethical approval of the University Hospital Ghent (reference number B670201836585).

\section{Results}

\subsection{Water Kefir Beverages Induced a Change in Metabolic Microbial Activity}

In general, water kefir, pasteurization and donor had a significant effect on most of the microbial metabolic markers, while type of water used to prepare the kefir only affected lactate, ammonia and BCFA (Table 1). 


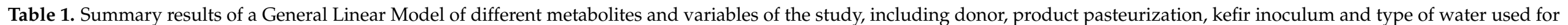
kefir preparation.

\begin{tabular}{|c|c|c|c|c|c|c|c|c|c|c|}
\hline & & $\begin{array}{c}\Delta 6 \mathrm{~h} \\
\text { Acetate } \\
(\mathrm{mM})\end{array}$ & $\begin{array}{c}\Delta 6 \mathrm{~h} \\
\text { Propionate } \\
(\mathrm{mM})\end{array}$ & $\begin{array}{c}\Delta 24 \mathrm{~h} \\
\text { Butyrate } \\
(\mathrm{mM})\end{array}$ & $\begin{array}{l}\Delta 24 \mathrm{~h} \\
\mathrm{BCFA} \\
(\mathrm{mM})\end{array}$ & $\begin{array}{l}\Delta 6 \mathrm{~h} \\
\text { SCFA } \\
(\mathrm{mM})\end{array}$ & $\begin{array}{c}\Delta 24 \mathrm{~h} \\
\text { Ammonia } \\
(\mathrm{mg} / \mathrm{L})\end{array}$ & $\begin{array}{c}\Delta 6 \mathrm{~h} \\
\text { Lactate } \\
(\mathrm{mM})\end{array}$ & $\begin{array}{c}\Delta 6 \mathrm{~h} \\
\mathrm{pH}\end{array}$ & $\begin{array}{c}\Delta 6 \mathrm{~h} \\
\mathrm{Gas} \\
(\mathrm{kPa})\end{array}$ \\
\hline \multirow{3}{*}{ Pasteurization } & R-sq & $92.93 \%$ & $89.69 \%$ & $79.61 \%$ & $50.06 \%$ & $98.83 \%$ & $98.03 \%$ & $23.33 \%$ & $91.99 \%$ & $88.86 \%$ \\
\hline & NP & $19.72 \pm 1.77$ & $9.25 \pm 1.02$ & $3.8 \pm 0.26$ & $1.10 \pm 0.27$ & $30.54 \pm 2.22$ & $262.92 \pm 13.6$ & $1.84 \pm 1.29$ & $-0.36 \pm 0.05$ & $26.20 \pm 2.87$ \\
\hline & $p$ & $28.25 \pm 2.59$ & $12.58 \pm 1.54$ & $5.3 \pm 0.56$ & $0.77 \pm 0.21$ & $42.27 \pm 2.49$ & $192.45 \pm 15.40$ & $1.71 \pm 0.31$ & $-0.70 \pm 0.08$ & $28.72 \pm 3.05$ \\
\hline \multirow[t]{3}{*}{ Donor } & $p$-Value & $<0.001$ & $<0.001$ & 0.009 & 0.087 & $<0.001$ & 0.003 & 0.55 & 0.04 & $<0.001$ \\
\hline & $\mathrm{A}$ & $24.19 \pm 2.82$ & $8.45 \pm 0.94$ & $5.3 \pm 0.72$ & $1.04 \pm 0.25$ & $33.46 \pm 3.69$ & $216.42 \pm 25$ & $2.67 \pm 1.16$ & $-0.56 \pm 0.12$ & $23.87 \pm 2.00$ \\
\hline & $\mathrm{C}$ & $28.65 \pm 3.78$ & $8.95 \pm 0.45$ & $3.8 \pm 0.53$ & $0.53 \pm 0.06$ & $40.23 \pm 4.17$ & $232.21 \pm 23.94$ & $1.30 \pm 1.52$ & $-0.57 \pm 0.12$ & $36.50 \pm 3.19$ \\
\hline \multirow[t]{3}{*}{ Kefir } & $p$-Value & $<0.001$ & 0.001 & $<0.001$ & 0.37 & $<0.001$ & $<0.001$ & 0.02 & $<0.001$ & $<0.001$ \\
\hline & $\mathrm{K} 1$ & $18.94 \pm 1.50$ & $9.11 \pm 1.02$ & $3.5 \pm 0.25$ & $1.07 \pm 0.23$ & $19.69 \pm 1.88$ & $266.67 \pm 10.72$ & $3.60 \pm 0.86$ & $-0.34 \pm 0.04$ & $22.04 \pm 2.00$ \\
\hline & $\mathrm{K} 2$ & $29.04 \pm 4.28$ & $12.72 \pm 2.05$ & $5.6 \pm 0.71$ & $0.80 \pm 0.07$ & $19.90 \pm 5.60$ & $188.7 \pm 17.81$ & $-0.04 \pm 0.66$ & $-0.72 \pm 0.11$ & $32.88 \pm 4.61$ \\
\hline \multirow[t]{3}{*}{ Water } & $p$-Value & 0.30 & 0.41 & 0.44 & 0.02 & 0.003 & 0.021 & 0.03 & 0.47 & 0.91 \\
\hline & $\mathrm{H}$ & $24.76 \pm 2.20$ & $11.30 \pm 1.52$ & $4.7 \pm 0.42$ & $1.33 \pm 0.39$ & $20.48 \pm 2.78$ & $233.68 \pm 16.07$ & $0.05 \pm 0.59$ & $-0.55 \pm 0.06$ & $29.00 \pm 2.95$ \\
\hline & $\mathrm{V}$ & $23.21 \pm 2.52$ & $10.53 \pm 1.40$ & $4.4 \pm 0.49$ & $0.54 \pm 0.08$ & $19.12 \pm 2.35$ & $221.68 \pm 16.22$ & $3.51 \pm 0.89$ & $-0.51 \pm 0.08$ & $25.92 \pm 2.64$ \\
\hline
\end{tabular}


Considering all the kefir products independently of the kefir source or pasteurization, total short-chain fatty acids were consistently increased by kefir treatments $\left(\Delta_{6} \mathrm{~h}\right.$ $33.7 \pm 3 \mathrm{mM})$ compared to the control $\left(\Delta_{6 \mathrm{~h}} 14.9 \pm 0.8 \mathrm{mM}\right)$ (Figure $\left.2 \mathrm{~A}\right)$. This effect was observed in short-term incubation $\left(\Delta_{6 \mathrm{~h}}\right)$ but was not significant at longer incubation times $\left(\Delta_{24} \mathrm{~h}\right)$. Changes in total SCFA were primarily caused by the major metabolite acetate, which showed the same trend described above (Figure 2A, Table 1). Propionate was also significantly increased by kefir $\left(\Delta_{6} \mathrm{~h} 10.2 \pm 1.4 \mathrm{mM}\right)$ compared to the control condition $\left(\Delta_{6} \mathrm{~h} 3.9 \pm 0.3 \mathrm{mM}\right)$ (Figure 2B). Butyrate levels were only increased by kefir at $24 \mathrm{~h}\left(\Delta_{24} \mathrm{~h}\right.$ $4.2 \pm 0.5 \mathrm{mM})$ compared to control $\left(\Delta_{24 \mathrm{~h}} 2.7 \pm 0.5 \mathrm{mM}\right)(p<0.04)$. BCFA did not differ at $\Delta 6 \mathrm{~h}$ or $\Delta 24 \mathrm{~h}$. Consistently with observed changes in SCFA, a decrease in $\mathrm{pH}\left(\Delta_{6} \mathrm{~h}\right.$ $-0.5 \pm 0.09)$ and increased levels of lactate $\left(\Delta_{6 \mathrm{~h}} 3 \pm 0.6 \mathrm{mM}\right)$ and gas production $\left(\Delta_{6} \mathrm{~h}\right.$ $25.1 \pm 2.9 \mathrm{kPa}$ ) were observed in kefir-exposed reactors (Figure 2C,E). As a marker of proteolytic fermentation, ammonia levels were significantly reduced by kefir $\left(\Delta_{24} \mathrm{~h}\right.$ 289.4.7 $\pm 18.5 \mathrm{mg} / \mathrm{L})$, compared to the control condition $\left(\Delta_{24} \mathrm{~h} 380.4 \pm 5.3 \mathrm{mg} / \mathrm{L}\right)$ (Figure $\left.2 \mathrm{~F}\right)$.

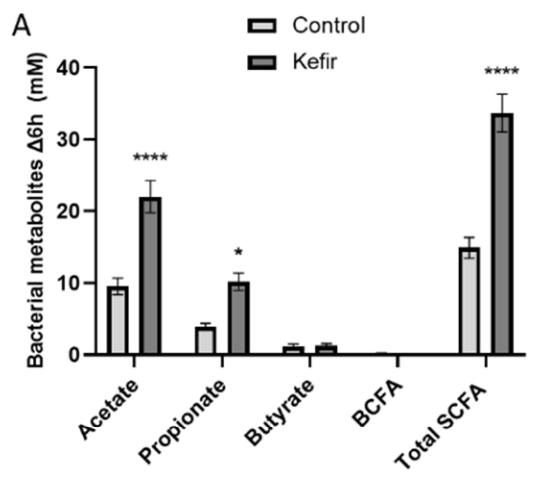

B
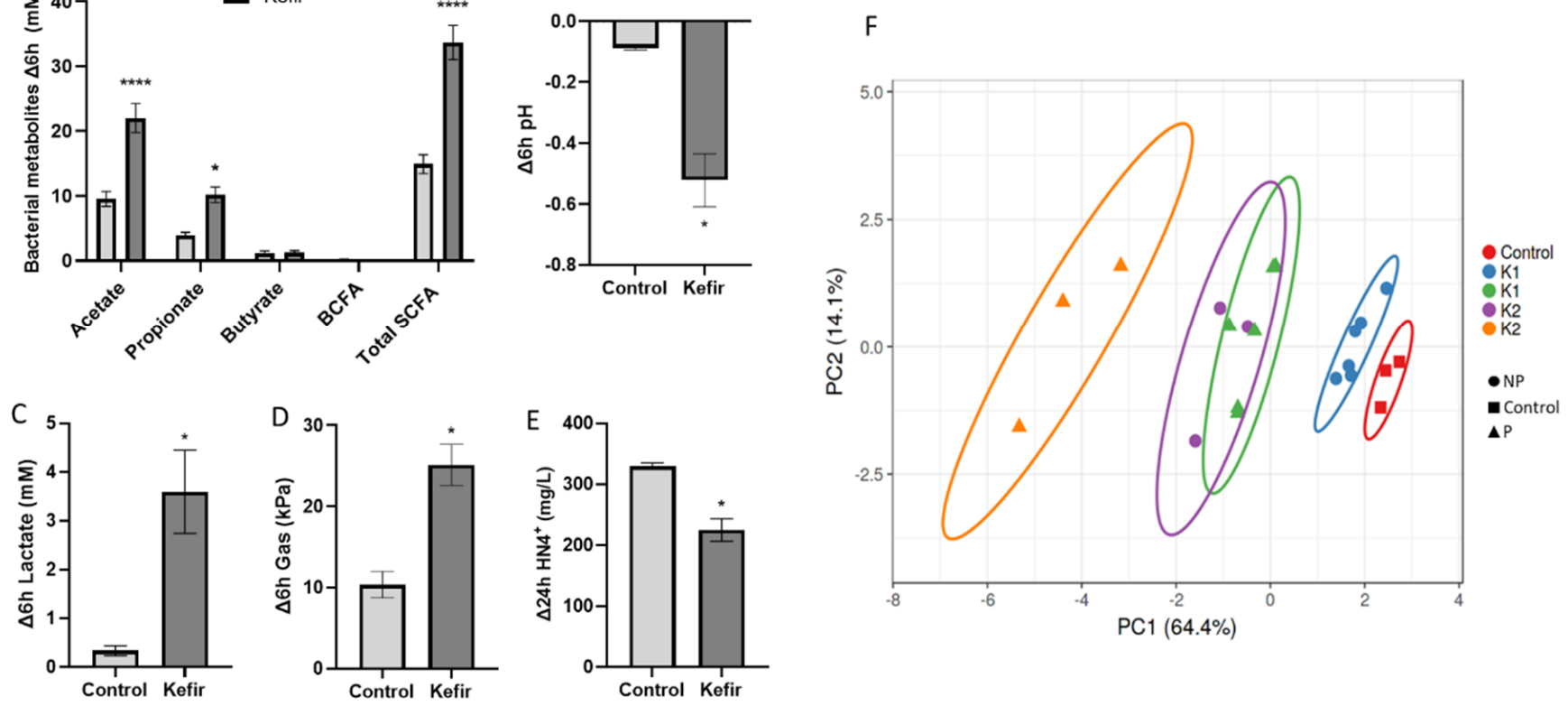

Figure 2. Effect of kefir supplementation on bacterial-derived metabolites. (A-E) Bars represent the delta change at $6 \mathrm{~h}$ $(\triangle 6 \mathrm{~h})$ for SCFA and BCFA (A,B), $\mathrm{pH}(\mathbf{C})$, lactate (D) and gas (E), and at $24 \mathrm{~h}(\Delta 24 \mathrm{~h})$ for ammonia. Values are expressed as mean \pm SEM of control $(n=3)$ or kefir-treated $(n=9)$ reactors. Significant differences are marked with asterisks $\left({ }^{*} p<0.05\right.$, **** $p<0.0001)$. (F) Principal Component Analysis plot of microbial metabolic markers, including absolute values of $\mathrm{pH}$, gas, lactate, SCFA, BCFA and ammonia at 6, 24 and $48 \mathrm{~h}$. Ellipses are drawn at 95\% confidence interval.

When analyzing the pasteurization effect on microbial metabolic products, acetate and propionate were higher in pasteurized samples than in non-pasteurized ones at $6 \mathrm{~h}$ $(p<0.001$, Table 1). Butyrate levels were significantly increased in pasteurized samples at $24 \mathrm{~h}$ (Table 1), with no significant effects at other time points. Contrarily, ammonia was significantly lower in reactors exposed to pasteurized samples at $24 \mathrm{~h}$ (Table 1 ).

When considering each product independently, a different response was observed for K1 and K2 (Table 1), with the highest effect on microbial metabolic activity observed for K2_P (Figure 2F, Supplementary Figure S1). Consistently, K2_P significantly increased acetate $\left(\Delta_{6 \mathrm{~h}} 48.3 \pm 1.7 \mathrm{mM}\right)$, propionate $\left(\Delta_{6 \mathrm{~h}} 13.8 \pm 2 \mathrm{mM}\right)$ and butyrate $\left(\Delta_{24} \mathrm{~h}\right.$ $6.8 \pm 0.5 \mathrm{mM})$ and reduced proteolytic fermentation markers BCFA $\left(\Delta_{24 \mathrm{~h}} 0.4 \pm 0.1 \mathrm{mM}\right)$ and ammonia $\left(\Delta_{24 \mathrm{~h}} 144.1 \pm 4.5 \mathrm{mg} / \mathrm{L}\right.$ ), compared to control condition (Supplementary Figure S1). 
Type of water used in kefir preparation influenced BCFA production, with higher levels observed in $\mathrm{H}(1.3 \pm 0.4 \mathrm{mM})$ compared to $\mathrm{V}(0.5 \pm 0.1 \mathrm{mM})$ (Table 1) and lactate $\left(\Delta_{6 \mathrm{~h}} \mathrm{H}=0.05 \pm 0.6 \mathrm{mM} ; \mathrm{V}=3.5 \pm 0.9 \mathrm{mM}\right)($ Table 1$)$.

\subsection{Water Kefir Beverages Induced a Shift in Microbial Structure of Healthy Adults}

In our setup, the main effects on microbial communities in vitro were time and donor (Supplementary Figure S2). Overall, the microbial communities from control condition and kefir treatments clustered separately (Figure 3A), however, the effect of kefir starter culture was not significant using a multivariate analysis (Adonis based on Bray-Curtis distance $p=0.457)$.
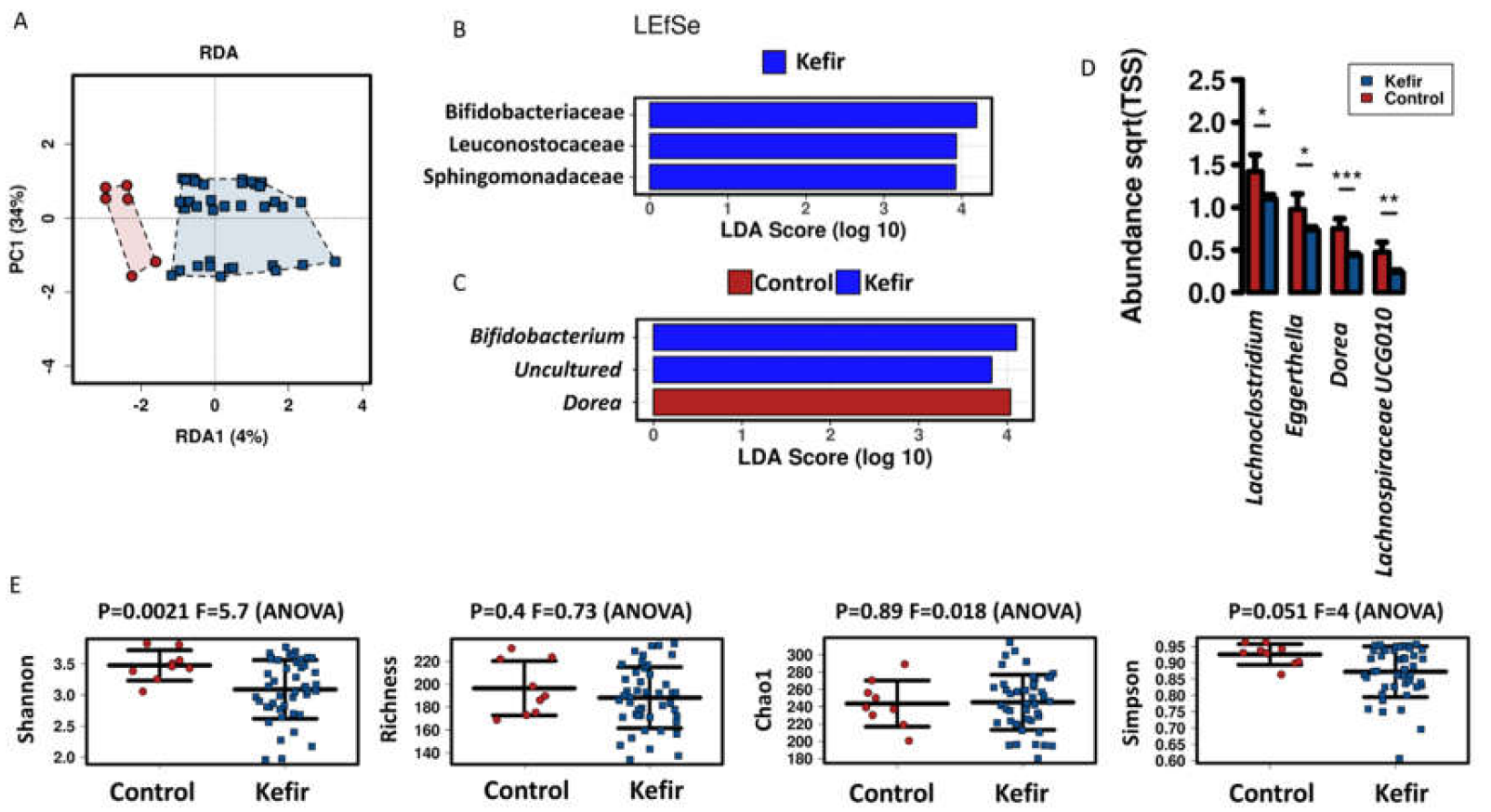

Figure 3. Effect of kefir on microbial communities in vitro. (A) Redundancy analysis (RDA) plot of microbial community of control and kefir-exposed reactors, including three different donors and two time points ( $24 \mathrm{~h}$ and $48 \mathrm{~h}$ ). Linear discriminant effect size (LEfSe) analysis at family (B) and genus (C) level. (D) Bar plot of the abundance at genus level of statistically significant $\left[p<0.05\left(^{*}\right), p<0.01\left(^{* *}\right), p<0.001\left(^{* * *}\right)\right]$ differences between control and kefir condition. (E) Strip charts representing Shannon, Richness, Chao1 and Simpson's index at OTU level. Sqrt(TSS) = square root total sum of squares.

When performing a linear discriminant analysis effect size (LEfSe) analysis at family level, kefir-treated reactors were enriched (LDA > 3) in Bifidobacteriaceae, Leuconostocaceae and Sphingomonadaceae (Figure 3B) compared to control samples. LEfSe analysis at the genus level showed enrichment of Dorea in the control group, while Bifidobacterium and uncultured bacterium were enriched in kefir reactors. The abundance of Lachnoclostridium, Eggerthella, and Lachnospiraceae_UCG010 was also reduced by kefir (Figure 3D). At OTU level, Shannon index showed a significant decrease with kefir, whereas other diversity indices were not significantly affected by kefir treatments (Figure 3E).

When looking specifically at the effect of pasteurization on microbial communities, specific taxa were differentially modulated. Pasteurized kefir caused a significant enrichment on Actinobacteria phylum and decreased Bacteroidota compared to non-pasteurized products (Figure 4A). At the family level, pasteurization induced an enrichment of Bifidobacteriaceae compared to non-pasteurized samples, which contrarily showed a higher abundance of Sphingomonadaceae and Esysipelatoclostridiaceae (Figure 4B). A reduction of minor genera like Anaerococcus, Family_XIII_AD3011_group, Fusicatenibacter, Holdemanella, Lachnospira, Lachnospiraceae_ND3007_group, Marvinbryantia and Roseburia was observed in pasteurized samples as compared to non-pasteurized ones. Consistently, Bifidobac- 
terium genus was enriched in pasteurized samples (Figure 4C). Shannon index was significantly reduced by kefir treatments, especially from pasteurized samples, while richness, Chao1 and Simpson index were not significantly affected by the treatments (Figure 4D). Erysipelotrichaceae_unclassified was a unique feature detected in non-pasteurized samples and Peptostreptococcus genus was present only in water kefir-treated reactors (Figure 4E).

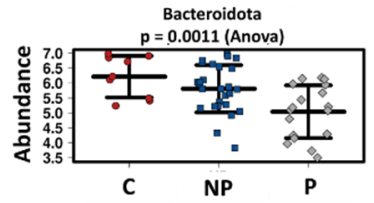

B

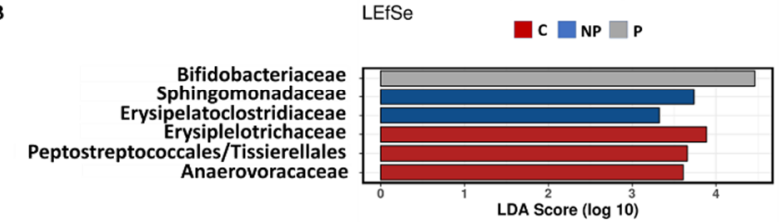

c

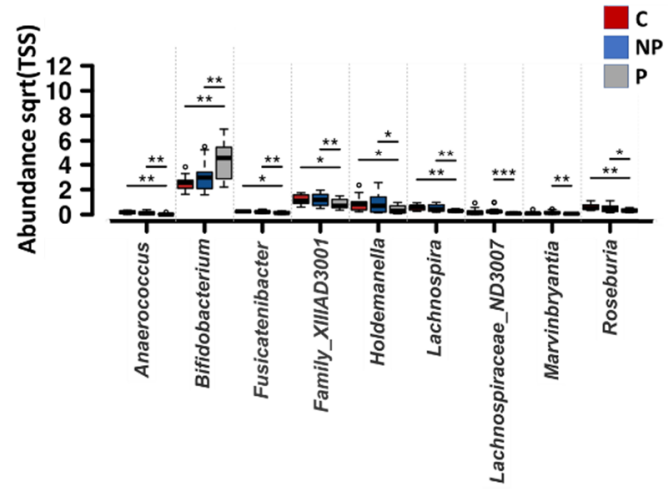

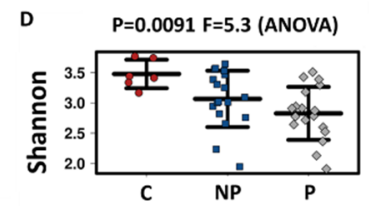
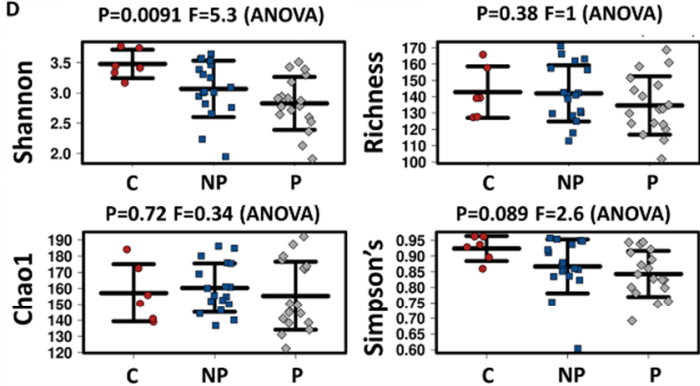

$P=0.089 \mathrm{~F}=2.6$ (ANOVA)
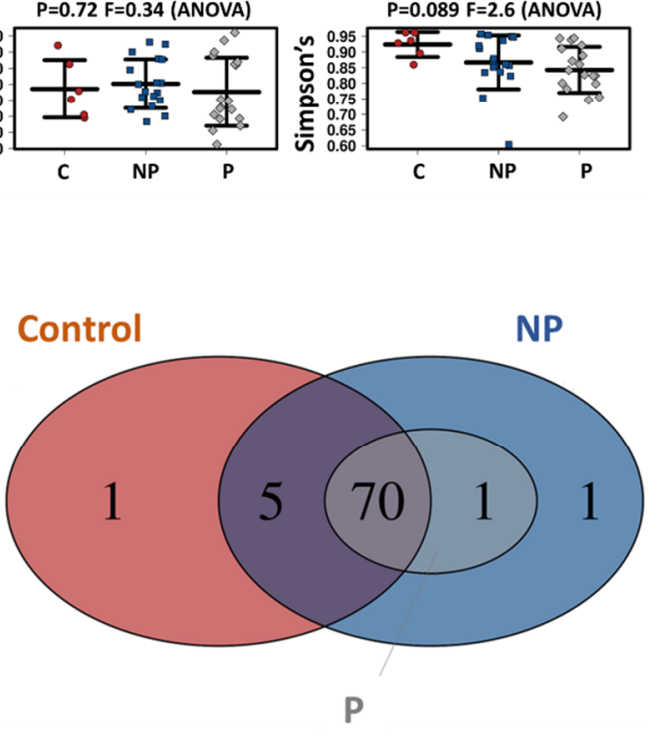

Figure 4. Effet of pasteurization of kefir on microbial modulation in vitro, including three different donors and two time points ( $24 \mathrm{~h}$ and $48 \mathrm{~h}$ ). (A) Strip charts at phylum level of statistically significant differences between non-pasteurized and pasteurized samples. (B) Linear discriminant effect size (LEfSe) analysis family level. (C) Box plot of the abundance at genus level of statistically significant $\left[p<0.05\left(^{*}\right), p<0.01\left(^{* *}\right), p<0.001\left(^{* * *}\right)\right]$ differences between non-pasteurized and pasteurized samples. (D) Strip charts of Shannon, Richness, Chao1 and Simpson's index. (E) Core microbiota plot at genus level, showing unique and common features to the different treatment groups. Sqrt(TSS) = square root total sum of squares.

When looking at the two specific products used in this research, the main differences observed for kefir were induced by K2, which significantly reduced Desulfobacterota and Bacteroidota phylum compared to K1 and control conditions (Supplementary Figure S3). Bifidobacteriaceae enrichment was associated with $\mathrm{K} 2$ treatment, mainly due to changes in OTU2 (Bifidobacterium adolescentis/faecalis) (Supplementary Tables S5 and S6).

\subsection{Pasteurization Had a Significant Effect on Ethanol Production and Yeast Levels}

In the control condition, EtOH levels were lower $(0.6 \pm 0.2 \mathrm{mM}, 24 \mathrm{~h})$ than in water kefir-treated reactors $(23.1 \pm 8.8 \mathrm{mM}, 24 \mathrm{~h})(p<0.0001)$. The highest levels of EtOH were quantified on colonic incubations exposed to non-pasteurized products ( $28.9 \pm 5 \mathrm{mM}, 24 \mathrm{~h})$, with the highest values observed for K1. Pasteurized samples showed a consistent decrease in EtOH levels $(16.9 \pm 6.9 \mathrm{mM} ; 24 \mathrm{~h})$ compared to non-pasteurized ones (Figure 5A) $(p<0.001)$. 

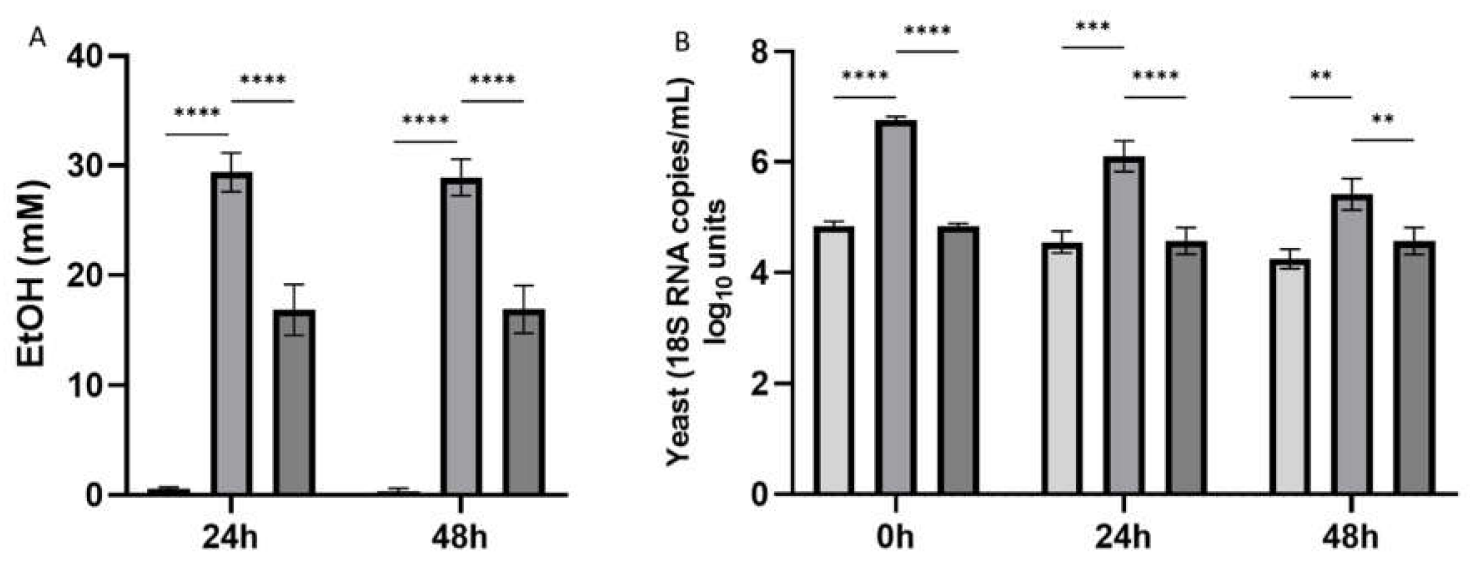

Figure 5. Effect of kefir products on ethanol and yeast levels. (A) Bars represent mean \pm SEM $(n=3)$ of EtOH (mM) levels different reactors exposed to non-pasteurized and pasteurized kefir products for 24 and $48 \mathrm{~h}$. (B) Bars represent the mean \pm SEM of yeast 18 S RNA copies/mL quantified by qPCR at different time points. Significant differences between control condition and treatments or between non-pasteurized and pasteurized products are marked by $\left({ }^{* *}\right),\left({ }^{* * *}\right)$ and $\left({ }^{* * * *}\right)$ $p<0.05, p<0.01, p<0.001$ and $p<0.0001$, respectively.

Quantification of 18S RNA copies showed similar values for control condition at the different time points ( $4.6 \pm 0.2$ copies $/ \mathrm{mL} \log _{10}$ units), while non-pasteurized products significantly increased $18 \mathrm{~S}$ RNA copies $\left(\mathrm{K} 1=5.8 \pm 0.5\right.$ copies $/ \mathrm{mL} \log _{10}$ units; $\mathrm{K} 2=$ $6.7 \pm 0.1$ copies $/ \mathrm{mL}$ ). Pasteurization significantly reduced $18 \mathrm{~S}$ RNA copies, especially in kefir K1, which shows similar levels to control (4.4 \pm 0.2 copies $/ \mathrm{mL} \log _{10}$ units), while pasteurized K2 still had higher levels at $24 \mathrm{~h}$ and $48 \mathrm{~h}$ compared to the control condition (5.5 \pm 0.06 copies $/ \mathrm{mL} \log _{10}$ units). The amount of yeast in non-pasteurized product decreased over time.

\subsection{Water Kefir Diminished Inflammation-Induced Intestinal Epithelial Barrier Disruption}

Cells exposed to microbial metabolites from kefir-treated reactors had significantly higher $(p=0.019)$ percentages of TEER $(89 \pm 2 \%)$ compared to the initial values than the control condition $(81 \pm 6 \%)$. Pasteurization increased the effect of kefir products on TEER enhancement ( $p=0.014)$, with values of $92 \pm 3 \%$ and $86 \pm 3 \%$ for pasteurized and non-pasteurized products, respectively, with pasteurized K2 showing the highest increase on TEER values (93 $\pm 4 \%$ ) (Figure $6 \mathrm{~A}$, Supplementary Figure S4).

\subsection{Immunomodulatory Activity of Water Kefir at the Intestinal Level}

In general, when considering all treatments together, NF- $\mathrm{kB}$ activity was not significantly modified by kefir (Figure 6). However, colonic batch suspensions of all pasteurized products increased NF- $\mathrm{kB}$ activity, with the strongest effects seen for $\mathrm{K} 1\left(0.7 \pm 0.03 \mathrm{OD}_{630}\right)$ (Supplementary Figure S4).

Overall, pasteurization had a significant effect on modulatory activity of kefir products. Cells exposed to pasteurized kefir products significantly increased IL10 (kefir = $53 \pm 0.7 \mathrm{pg} / \mathrm{mL}$; control $=31 \pm 0.2 \mathrm{pg} / \mathrm{mL}, p<0.001$ ) and IL1 $\beta$ (kefir $=389 \pm 4.7 \mathrm{pg} / \mathrm{mL}$; control $=300 \pm 1.5 \mathrm{pg} / \mathrm{mL}, p=0.01$ ) (Figure 6).

The effect of different parameters, including inoculum, pasteurization and water on epithelial barrier integrity, NF- $\mathrm{kB}$ activation and immunomodulatory activity in each donor is presented in supplementary Figures S5 and S6. 

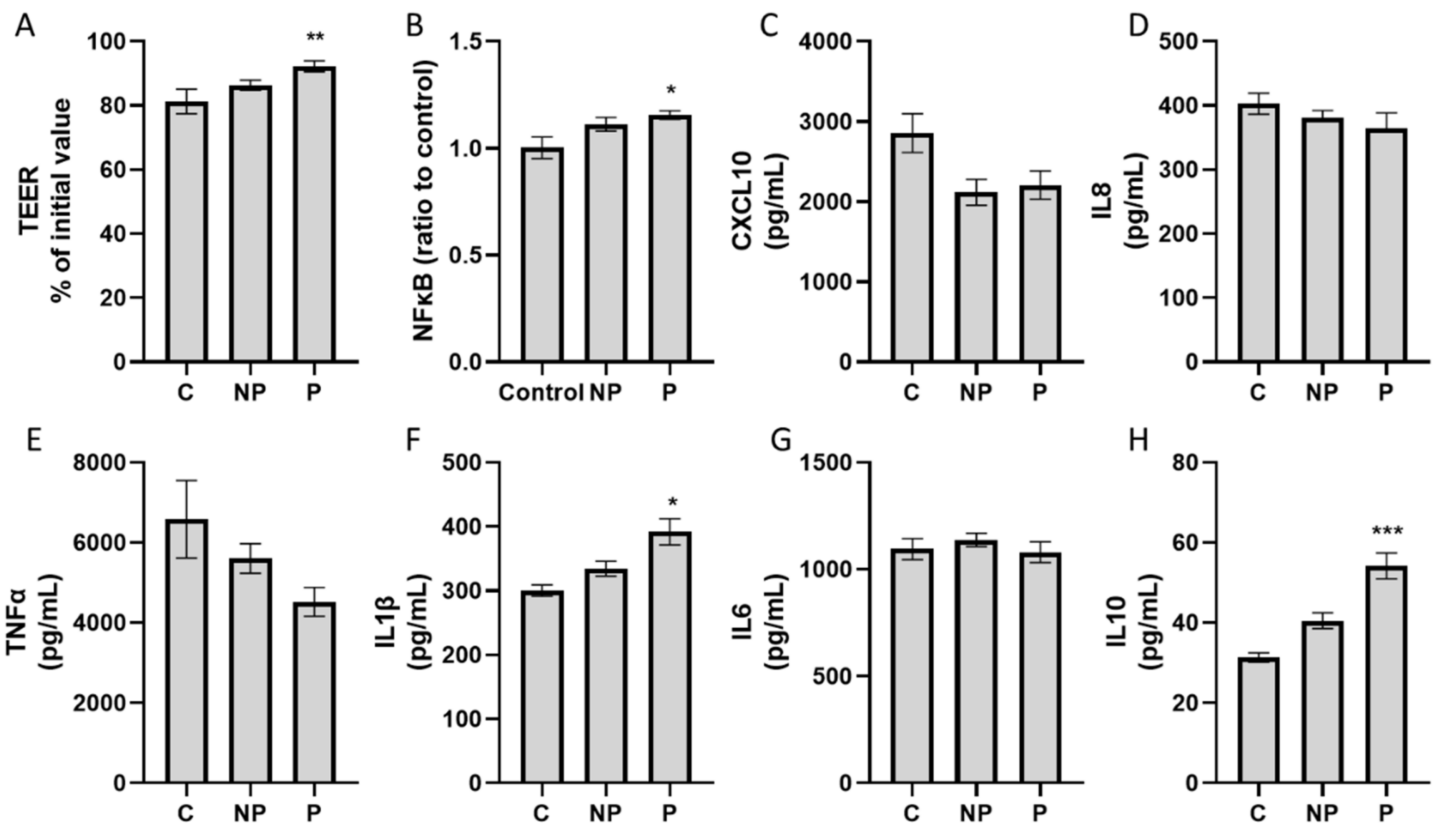

Figure 6. Effect of kefir on the intestinal barrier and immunomodulation. Bars represent the mean \pm SEM ( $n \geq 3$ ) for TEER percentages of the initial value (A), NF- $\kappa \beta$ activity of THP1 cells (B), CXCL10 (C), IL8 (D), TNF $\alpha$ (E), IL1 $\beta$ (F), IL6 (G) and IL10 (H). Significant differences between control condition and treatments marked by $\left({ }^{*}\right),\left({ }^{* *}\right)$ and $\left({ }^{* * *}\right)$ for $p<0.05, p<0.01$ and $p<0.001$, respectively.

\section{Discussion}

Modulation of composition and metabolic activity of gut microbiota from three healthy donors by different kefir products was evaluated using a short-term simulation of the colonic fermentation process.

Despite significant interindividual differences in basal microbiota, kefir supplementation showed a consistent potential to modulate microbial activity in vitro, likely by adding fermentative substrates and microorganisms to the background colonic media. Overall, all products increased short-chain fatty acids and lactate and reduced ammonia production, with the highest effect observed for pasteurized K2, which increased health-promoting propionate and butyrate. Major SCFAs, such as acetate, propionate and butyrate, are important metabolites for intestinal homeostasis, metabolic control, and immune programming [46-49]. Specifically, butyrate is the primary source of energy for colonocytes and is involved in maintaining the epithelial barrier function [50,51]. Increased fecal SCFAs were also observed in human kefir-intervention studies [52]. Along with increases in beneficial SCFAs, kefir reduced by-products of protein and nitrogen metabolism. Urease producing bacteria and glutaminase positive bacteria significantly mediate ammonia production in the colon, which is known to have negative effects on epithelial health [53]. Taken together, these results potentially link kefir intake with positive regulation of the colonic microenvironment, inducing beneficial SCFAs production while reducing detrimental proteolytic fermentation compounds.

Linked to microbial metabolic activity, changes in ecosystem structure were also detected, with the Bifidobacteriaceae family being consistently increased by water kefir. Bifidobacterium spp. are early colonizers of the human gut and are associated with a healthy condition [54]. Reduced Bifidobacteriaceae populations have been described in different pathological conditions such as allergy or inflammatory bowel disease [54-56]. Water kefir-related increases of Bifidobacteriaceae in our setup likely explain the increase of acetate and lactate production, which can cross-feed commensal butyrate or propionateproducing anaerobes [57]. This in turn may explain the finding of increased butyrate 
at $24 \mathrm{~h}$, whereas acetate is not different from control. Pasteurized products had a more substantial bifidogenic effect than non-pasteurized counterparts, therefore the observed increase in Bifidobacterium spp might be linked to the stimulation of resident bifidobacterial populations. This observation also suggests that the thermal degradation of water kefir yeast and bacterial microbial populations makes available different carbon sources that promote Bifidobacterium growth, such yeast glycans [58,59]. Quantification of yeasts by qPCR and significant reduction of ethanol levels evidenced a degradation of yeasts during pasteurization process and enzymatic machinery in Bifidobacterium spp. have been reported to selectively uptake carbohydrates from glycans. Significant increases in the relative abundance of Actinobacteria have been reported in a parallel-group, randomized, controlled clinical trial setting with patients with metabolic syndrome receiving milk kefir compared to unfermented milk during 12 weeks [60], a trait also observed in this study. Specific components of water kefir responsible for its effects in animal and human intervention studies have not been fully determined but levan increased bifidobacteria levels in an in vivo rat model supplemented for 90 days with different doses of levan [61]. Levan is a water-soluble fructose polymer produced by bacteria and archaea via secreted or cell-wall anchored, extracellular levansucrases [62]. In our research, OTU2, related to Bifidobacterium adolescentis/faecalis was significantly induced by water kefir, especially by pasteurized samples, extending the paraprobiotic/postbiotic application of water kefir products and suggesting a species-specific bifidogenic effect depending on background host microbiota. In parallel to Bifidobacterium spp. stimulation, kefir induced a decrease in the abundance of Dorea genus, a commensal member of the gut microbiota, which is over-represented in individuals with asthma, type 2 diabetes [9,10] and obese mice [63].

Multiple mechanisms have been previously described for the modulation of gut microbiota by probiotics or paraprobiotics to beneficially affect host health, including microbe-microbe interaction of kefir strains with intestinal microorganisms, microbe-host interaction with intestinal epithelium, modulation of mucus production or epithelial barrier function, local or distal immunomodulation or effects on gut-organs communication (e.g., gut-brain, gut-liver, gut-lung axis) [64]. We demonstrated the protective effects of water kefir products on inflammation-induced intestinal barrier disruption, with the most potent effect observed in pasteurized product K2. This result is in line with the highest modulatory activity of pasteurized products on gut microbiota but can also be a cause of the increased release of bioactive molecules derived from water kefir yeast and bacteria during inactivation. The increased SCFA production by water kefir, especially pasteurized K2 kefir, is a potential molecular mechanism for the enhanced gut barrier $[65,66]$.

Consistently, pasteurized kefirs enhanced intestinal barrier function and promoted anti-inflammatory IL-10 production. Microbial metabolites, like butyrate, acetate or propionate, but also yeast-derived molecules could be involved in the upregulation of IL-10 observed in our model. IL-10 is a central cytokine in maintaining mucosal tolerance, signaling different lymphocyte $\mathrm{T}$ subpopulations, downregulating $\mathrm{TNF} \alpha$, and influencing selective colonization of the gut $[67,68]$ and it has been proposed as a target for reducing gut inflammation [51]. Butyrate has been shown to enhance IL-10 secretion in human monocytes, and different Saccharomyces strains also showed a stimulatory effect on IL-10 production by human peripheral blood mononuclear cells [69]. The same authors proposed that yeast regulation of gut inflammation in a mouse model may be mediated by reinforcement of the intestinal barrier, a mechanism supported by a recent study in piglets that showed how yeast culture improved the expression of tight junction proteins [70].

Pasteurized water kefir also induced activation of NF- $\kappa$ B and secretion of IL-1 $\beta$, both usually considered pro-inflammatory markers. NF- $\mathrm{kB}$ regulates inflammation, immune responses, cell proliferation, survival, and apoptosis, and it is considered a key signaling molecule in maintaining epithelial barrier and immune homeostasis [71], while dysregulated IL-1 $\beta$ production has been linked to multiple inflammatory conditions [72]. However, a complex cross-regulation between pro- and anti-inflammatory cytokines occurs physiologically in the gut. For example, intestinal macrophage-derived IL-1 $\beta$ produced 
in response to commensal stimuli are key in maintaining oral tolerance and generating homeostasis-promoting regulatory $\mathrm{T}$ cells [72]. The effect of pasteurization on modulation of different cytokines suggests a major effect of water kefir processing on shifting the immune response in vitro, and due to the complex microbial nature of the product, further characterization of immunomodulatory molecules is proposed.

\section{Conclusions}

Most of the research involving pre and probiotic properties of kefir is based on milk kefir products, while this research provides novel information on potential modulatory effect of water kefir on human gut microbiota. Our study using an artificial colon set up suggests beneficial effects of water kefir consumption through SCFA production, bifidobacteria induction and epithelial barrier enhancement, while limitations on translatability and interindividual variability will require validation in clinical settings. Intriguingly, the observed benefits are enhanced by pasteurization, supporting water kefir derived products as paraprobiotics/postbiotics with potential health benefits and the added value of extended shelf life and stability of the product.

Supplementary Materials: The following are available online at https: / www.mdpi.com/article / 10.3390/nu13113897/s1. Figure S1: Short-term effect of different kefir products on microbial activity of healthy donors. Figure S2: Discriminant Analysis of Principal Components and Adonis based on Bray-Curtis distance for time and donor at family level. Figure S3: Effect of different starting cultures of water kefir on microbial structure in vitro. Figure S4: Effect of different products on epithelial barrier and immune modulation. Figure S5: Effect of colonic batch suspensions on transepithelial electrical resistance (TEER) of the Caco-2/THP1-BlueTM co-cultures (A) and NFK $\beta$ activity of THP1-Blue ${ }^{\mathrm{TM}}$ cells (B), including interindividual differences. Figure S6: Effect of colonic batch suspensions on secretion of IL-6 (A), IL-10 (B), IL-1 $\beta$ (C), TNF- $\alpha$ (D), CXCL10 (E) and IL-8 (F) including interindividual differences. Table S1: Composition of different products used in this research, including sucrose, fructose, lactic acid, acetic acid, ethanol, glucose and total sugar content, and bacterial quantification of and aerobic mesophilic bacteria (AMB), lactic acid bacteria (LAB) and yeasts. Table S2: Experimental conditions for quantification of aerobic mesophilic bacteria (AMB), lactic acid bacteria (LAB) and yeast. Table S3: Primers used for yeast quantification by qPCR. Table S4: Conditions used to quantify yeast populations by qPCR. Table S5: Average normalized microbial shifts and effects of the different treatment parameters (pasteurization, starting culture and type of water) on the most abundant OTUs detected after $24 \mathrm{~h}$ of incubation. Table S6: Average normalized microbial shifts and effects of the different treatment parameters (pasteurization, starting culture and type of water) on the most abundant OTUs detected after $48 \mathrm{~h}$ of incubation.

Author Contributions: Conceptualization, S.D., R.A.B., C.L.B., P.V.d.A.; methodology, J.D.M., J.G., and L.V., R.A.B., S.P.; formal analysis, J.G., L.V., M.C., S.D.; resources, S.D., C.L.B., R.A.B.; data curation, S.D., M.C.; writing-original draft preparation, M.C.; writing-review and editing, M.C., S.D., R.A.B., S.P.; visualization, M.C.; supervision, P.V.d.A., M.M.; project administration, M.M., C.L.B.; funding acquisition, S.D., C.L.B., R.A.B. All authors have read and agreed to the published version of the manuscript.

Funding: This research was funded by internal funds from Société des Produits Nestlé S.A., Switzerland.

Institutional Review Board Statement: Fecal samples of the healthy donors were collected according to the ethical approval of the University Hospital Ghent (reference number B670201836585).

Informed Consent Statement: Informed consent was obtained from all subjects involved in the study.

Data Availability Statement: The data that support the findings of this study are available from the corresponding authors, upon reasonable request.

Acknowledgments: Authors thank Julie De Munck, Evi Steppé, and Gilles De Rocker for their assistance in the lab, Florence Rochat and Karin Vidal for discussions on the experimental design and immunology tests and Nicole Pagé-Zoerkler for support in the preparation of water kefir. 
Conflicts of Interest: M.C., J.G., L.V., J.D.M. are employed by ProDigest. P.V.d.A. was employed by ProDigest during the development of this research. M.M. is CEO of ProDigest. S.D., C.L.B., S.P. and R.A.B. are employed by Société des Produits Nestlé S.A. The scientists employed by ProDigest and Société des Produits Nestlé were involved in the design of the study, analyses or interpretation of data, in the writing of the manuscript, and in the decision to publish the results.

\section{References}

1. Gensollen, T.; Iyer, S.S.; Kasper, D.L.; Blumberg, R.S. How Colonization by Microbiota in Early Life Shapes the Immune System. Science 2016, 352, 539-544. [CrossRef] [PubMed]

2. Levin, A.M.; Sitarik, A.R.; Havstad, S.L.; Fujimura, K.E.; Wegienka, G.; Cassidy-Bushrow, A.E.; Kim, H.; Zoratti, E.M.; Lukacs, N.W.; Boushey, H.A. Joint Effects of Pregnancy, Sociocultural, and Environmental Factors on Early Life Gut Microbiome Structure and Diversity. Sci. Rep. 2016, 6, 31775. [CrossRef] [PubMed]

3. Vatanen, T.; Kostic, A.D.; d’Hennezel, E.; Siljander, H.; Franzosa, E.A.; Yassour, M.; Kolde, R.; Vlamakis, H.; Arthur, T.D.; Hämäläinen, A.-M.; et al. Variation in Microbiome LPS Immunogenicity Contributes to Autoimmunity in Humans. Cell 2016, 165, 842-853. [CrossRef] [PubMed]

4. Tamburini, S.; Shen, N.; Wu, H.C.; Clemente, J.C. The Microbiome in Early Life: Implications for Health Outcomes. Nat. Med. 2016, 22, 713-722. [CrossRef]

5. Keeney, K.M.; Yurist-Doutsch, S.; Arrieta, M.-C.; Finlay, B.B. Effects of Antibiotics on Human Microbiota and Subsequent Disease. Annu. Rev. Microbiol. 2014, 68, 217-235. [CrossRef]

6. Ho, H.; Bunyavanich, S. Role of the Microbiome in Food Allergy. Curr. Allergy Asthma Rep. 2018, 18, 27. [CrossRef]

7. Arora, A.; Behl, T.; Sehgal, A.; Singh, S.; Sharma, N.; Bhatia, S.; Sobarzo-Sanchez, E.; Bungau, S. Unravelling the Involvement of Gut Microbiota in Type 2 Diabetes Mellitus. Life Sci. 2021, 273, 119311. [CrossRef]

8. Gurung, M.; Li, Z.; You, H.; Rodrigues, R.; Jump, D.B.; Morgun, A.; Shulzhenko, N. Role of Gut Microbiota in Type 2 Diabetes Pathophysiology. EBioMedicine 2020, 51, 102590. [CrossRef]

9. Li, Q.; Chang, Y.; Zhang, K.; Chen, H.; Tao, S.; Zhang, Z. Implication of the Gut Microbiome Composition of Type 2 Diabetic Patients from Northern China. Sci. Rep. 2020, 10, 5450. [CrossRef]

10. Wang, Q.; Li, F.; Liang, B.; Liang, Y.; Chen, S.; Mo, X.; Ju, Y.; Zhao, H.; Jia, H.; Spector, T.D. A Metagenome-Wide Association Study of Gut Microbiota in Asthma in UK Adults. BMC Microbiol. 2018, 18, 114. [CrossRef]

11. Fujimura, K.E.; Lynch, S.V. Microbiota in Allergy and Asthma and the Emerging Relationship with the Gut Microbiome. Cell Host Microbe 2015, 17, 592-602. [CrossRef]

12. Furet, J.-P.; Kong, L.-C.; Tap, J.; Poitou, C.; Basdevant, A.; Bouillot, J.-L.; Mariat, D.; Corthier, G.; Doré, J.; Henegar, C. Differential Adaptation of Human Gut Microbiota to Bariatric Surgery-Induced Weight Loss: Links with Metabolic and Low-Grade Inflammation Markers. Diabetes 2010, 59, 3049-3057. [CrossRef]

13. Hill, C.; Guarner, F.; Reid, G.; Gibson, G.R.; Merenstein, D.J.; Pot, B.; Morelli, L.; Canani, R.B.; Flint, H.J.; Salminen, S. The International Scientific Association for Probiotics and Prebiotics Consensus Statement on the Scope and Appropriate Use of the Term Probiotic. Nat. Rev. Gastroenterol. Hepatol. 2014, 11, 506-514. [CrossRef]

14. Marsh, A.J.; O'Sullivan, O.; Hill, C.; Ross, R.P.; Cotter, P.D. Sequence-Based Analysis of the Microbial Composition of Water Kefir from Multiple Sources. FEMS Microbiol. Lett. 2013, 348, 79-85. [CrossRef]

15. Gulitz, A.; Stadie, J.; Wenning, M.; Ehrmann, M.A.; Vogel, R.F. The Microbial Diversity of Water Kefir. Int. J. Food Microbiol. 2011, 151, 284-288. [CrossRef]

16. Verce, M.; De Vuyst, L.; Weckx, S. Shotgun Metagenomics of a Water Kefir Fermentation Ecosystem Reveals a Novel Oenococcus Species. Front. Microbiol. 2019, 10, 479. [CrossRef]

17. Neve, H.; Heller, K.J. The Microflora of Water Kefir: A Glance by Scanning Electron Microscopy. Kiel. Milchwirtsch. Forsch. 2002, 54, 337-349.

18. Lynch, K.M.; Wilkinson, S.; Daenen, L.; Arendt, E.K. An Update on Water Kefir: Microbiology, Composition and Production. Int. J. Food Microbiol. 2021, 345, 109128. [CrossRef]

19. Pidoux, M. The Microbial Flora of Sugary Kefir Grain (the Gingerbeer Plant): Biosynthesis of the Grain from Lactobacillus hilgardii Producing a Polysaccharide Gel. MIRCEN J. Appl. Microbiol. Biotechnol. 1989, 5, 223-238. [CrossRef]

20. Fiorda, F.A.; de Melo Pereira, G.V.; Thomaz-Soccol, V.; Rakshit, S.K.; Pagnoncelli, M.G.B.; de Souza Vandenberghe, L.P.; Soccol, C.R. Microbiological, Biochemical, and Functional Aspects of Sugary Kefir Fermentation-A Review. Food Microbiol. 2017, 66, 86-95. [CrossRef]

21. Prado, M.R.; Blandón, L.M.; Vandenberghe, L.P.S.; Rodrigues, C.; Castro, G.R.; Thomaz-Soccol, V.; Soccol, C.R. Milk Kefir: Composition, Microbial Cultures, Biological Activities, and Related Products. Front. Microbiol. 2015, 6, 1177. [CrossRef] [PubMed]

22. Bourrie, B.C.T.; Willing, B.P.; Cotter, P.D. The Microbiota and Health Promoting Characteristics of the Fermented Beverage Kefir. Front. Microbiol. 2016, 7, 647. [CrossRef]

23. Van de Wouw, M.; Walsh, A.M.; Crispie, F.; van Leuven, L.; Lyte, J.M.; Boehme, M.; Clarke, G.; Dinan, T.G.; Cotter, P.D.; Cryan, J.F. Distinct Actions of the Fermented Beverage Kefir on Host Behaviour, Immunity and Microbiome Gut-Brain Modules in the Mouse. Microbiome 2020, 8, 67. [CrossRef] [PubMed] 
24. Egea, M.B.; dos Santos, D.C.; de Oliveira Filho, J.G.; da Costa Ores, J.; Takeuchi, K.P.; Lemes, A.C. A Review of Nondairy Kefir Products: Their Characteristics and Potential Human Health Benefits. Crit. Rev. Food Sci. Nutr. 2020, 5, 1-17. [CrossRef] [PubMed]

25. Azizi, N.F.; Kumar, M.R.; Yeap, S.K.; Abdullah, J.O.; Khalid, M.; Omar, A.R.; Osman, M.A.; Mortadza, S.A.S.; Alitheen, N.B. Kefir and Its Biological Activities. Foods 2021, 10, 1210. [CrossRef] [PubMed]

26. Silva, K.R.; Rodrigues, S.A.; Filho, L.X.; Lima, Á.S. Antimicrobial Activity of Broth Fermented with Kefir Grains. Appl. Biochem. Biotechnol. 2009, 152, 316-325. [CrossRef] [PubMed]

27. Rocha-Gomes, A.; Escobar, A.; Soares, J.; Silva, A.; Dessimoni-Pinto, N.; Riul, T. Chemical Composition and Hypocholesterolemic Effect of Milk Kefir and Water Kefir in Wistar Rats. Rev. Nutr. 2018, 31, 137-145. [CrossRef]

28. Alsayadi, M.; Jawfi, Y.; Belarbi, M.; Soualem-Mami, Z.; Merzouk, H.; Sari, D.; Sabri, F.; Ghalim, M. Evaluation of AntiHyperglycemic and Anti-Hyperlipidemic Activities of Water Kefir as Probiotic on Streptozotocin-Induced Diabetic Wistar Rats. J. Diabetes Mellit. 2014, 4, 85-95. [CrossRef]

29. Eunice, B.; Aspiras, E.; Frances, R.; Flores, A.; Pareja, M. Hepatoprotective Effect of Fermented Water Kefir on Sprague-Dawley Rats (Rattus norvegicus) Induced with Sublethal Dose of Acetaminophen. Int. J. Curr. Sci. 2015, 2015, 18-28.

30. Talib, N.; Mohamad, N.E.; Yeap, S.K.; Hussin, Y.; Aziz, M.N.M.; Masarudin, M.J.; Sharifuddin, S.A.; Hui, Y.W.; Ho, C.L.; Alitheen, N.B. Isolation and Characterization of Lactobacillus spp. from Kefir Samples in Malaysia. Molecules 2019, 24, 2606. [CrossRef]

31. Marsaux, B.; Van den Abbeele, P.; Ghyselinck, J.; Prioult, G.; Marzorati, M.; Bogićević, B. Synbiotic Effect of Bifidobacterium Lactis CNCM I-3446 and Bovine Milk-Derived Oligosaccharides on Infant Gut Microbiota. Nutrients 2020, 12, 2268. [CrossRef]

32. Klindworth, A.; Pruesse, E.; Schweer, T.; Peplies, J.; Quast, C.; Horn, M.; Glöckner, F.O. Evaluation of General 16S Ribosomal RNA Gene PCR Primers for Classical and Next-Generation Sequencing-Based Diversity Studies. Nucleic Acids Res. 2012 , 41, e1. [CrossRef]

33. Chemidlin Prévost-Bouré, N.; Christen, R.; Dequiedt, S.; Mougel, C.; Lelièvre, M.; Jolivet, C.; Shahbazkia, H.R.; Guillou, L.; Arrouays, D.; Ranjard, L. Validation and Application of a PCR Primer Set to Quantify Fungal Communities in the Soil Environment by Real-Time Quantitative PCR. PLoS ONE 2011, 6, e24166. [CrossRef]

34. Nevel, S.V.; Koetzsch, S.; Weilenmann, H.-U.; Boon, N.; Hammes, F. Routine Bacterial Analysis with Automated Flow Cytometry. J. Microbiol. Methods 2013, 94, 73-76. [CrossRef]

35. Ghyselinck, J.; Verstrepen, L.; Moens, F.; den Abbeele, P.V.; Said, J.; Smith, B.; Bjarnason, I.; Basit, A.W.; Gaisford, S. A 4-Strain Probiotic Supplement Influences Gut Microbiota Composition and Gut Wall Function in Patients with Ulcerative Colitis. Int. J. Pharm. 2020, 587, 119648. [CrossRef]

36. Daguet, D.; Pinheiro, I.; Verhelst, A.; Possemiers, S.; Marzorati, M. Arabinogalactan and Fructooligosaccharides Improve the Gut Barrier Function in Distinct Areas of the Colon in the Simulator of the Human Intestinal Microbial Ecosystem. J. Funct. Foods 2016, 20, 369-379. [CrossRef]

37. Daigneault, M.; Preston, J.A.; Marriott, H.M.; Whyte, M.K.B.; Dockrell, D.H. The Identification of Markers of Macrophage Differentiation in PMA-Stimulated THP-1 Cells and Monocyte-Derived Macrophages. PLoS ONE 2010, 5, e8668. [CrossRef]

38. De Paepe, K.; Kerckhof, F.-M.; Verspreet, J.; Courtin, C.M.; Van de Wiele, T. Inter-Individual Differences Determine the Outcome of Wheat Bran Colonization by the Human Gut Microbiome. Environ. Microbiol. 2017, 19, 3251-3267. [CrossRef]

39. Cole, J.R.; Wang, Q.; Fish, J.A.; Chai, B.; McGarrell, D.M.; Sun, Y.; Brown, C.T.; Porras-Alfaro, A.; Kuske, C.R.; Tiedje, J.M. Ribosomal Database Project: Data and Tools for High Throughput RRNA Analysis. Nucleic Acids Res. 2013, 42, D633-D642. [CrossRef]

40. Schloss, P.D.; Westcott, S.L.; Ryabin, T.; Hall, J.R.; Hartmann, M.; Hollister, E.B.; Lesniewski, R.A.; Oakley, B.B.; Parks, D.H.; Robinson, C.J.; et al. Introducing Mothur: Open-Source, Platform-Independent, Community-Supported Software for Describing and Comparing Microbial Communities. Appl. Environ. Microbiol. 2009, 75, 7537-7541. [CrossRef]

41. Schloss, P.D.; Westcott, S.L. Assessing and Improving Methods Used in Operational Taxonomic Unit-Based Approaches for 16S RRNA Gene Sequence Analysis. Appl. Environ. Microbiol. 2011, 77, 3219-3226. [CrossRef]

42. Chen, W.; Zhang, C.K.; Cheng, Y.; Zhang, S.; Zhao, H. A Comparison of Methods for Clustering 16S RRNA Sequences into OTUs. PLoS ONE 2013, 8, e70837. [CrossRef]

43. Wang, Q.; Garrity, G.M.; Tiedje, J.M.; Cole, J.R. Naive Bayesian Classifier for Rapid Assignment of RRNA Sequences into the New Bacterial Taxonomy. Appl. Environ. Microbiol. 2007, 73, 5261-5267. [CrossRef]

44. Quast, C.; Pruesse, E.; Yilmaz, P.; Gerken, J.; Schweer, T.; Yarza, P.; Peplies, J.; Glöckner, F.O. The SILVA Ribosomal RNA Gene Database Project: Improved Data Processing and Web-Based Tools. Nucleic Acids Res. 2013, 41, D590-D596. [CrossRef]

45. Altschul, S.F.; Gish, W.; Miller, W.; Myers, E.W.; Lipman, D.J. Basic Local Alignment Search Tool. J. Mol. Biol. 1990, 215, 403-410. [CrossRef]

46. Parada Venegas, D.; De la Fuente, M.K.; Landskron, G.; González, M.J.; Quera, R.; Dijkstra, G.; Harmsen, H.J.M.; Faber, K.N.; Hermoso, M.A. Short Chain Fatty Acids (SCFAs)-Mediated Gut Epithelial and Immune Regulation and Its Relevance for Inflammatory Bowel Diseases. Front. Immunol. 2019, 10, 277. [CrossRef]

47. Hu, J.; Lin, S.; Zheng, B.; Cheung, P.C.K. Short-Chain Fatty Acids in Control of Energy Metabolism. Crit. Rev. Food Sci. Nutr. 2018, 58, 1243-1249. [CrossRef]

48. Schulthess, J.; Pandey, S.; Capitani, M.; Rue-Albrecht, K.C.; Arnold, I.; Franchini, F.; Chomka, A.; Ilott, N.E.; Johnston, D.G.W.; Pires, E.; et al. The Short Chain Fatty Acid Butyrate Imprints an Antimicrobial Program in Macrophages. Immunity 2019, 50, 432-445.e7. [CrossRef] 
49. González Hernández, M.A.; Canfora, E.E.; Jocken, J.W.E.; Blaak, E.E. The Short-Chain Fatty Acid Acetate in Body Weight Control and Insulin Sensitivity. Nutrients 2019, 11, 1943. [CrossRef]

50. Zheng, L.; Kelly, C.J.; Battista, K.D.; Schaefer, R.; Lanis, J.M.; Alexeev, E.E.; Wang, R.X.; Onyiah, J.C.; Kominsky, D.J.; Colgan, S.P. Microbial-Derived Butyrate Promotes Epithelial Barrier Function through IL-10 Receptor-Dependent Repression of Claudin-2. J. Immunol. 2017, 199, 2976-2984. [CrossRef]

51. Wang, R.X.; Lee, J.S.; Campbell, E.L.; Colgan, S.P. Microbiota-Derived Butyrate Dynamically Regulates Intestinal Homeostasis through Regulation of Actin-Associated Protein Synaptopodin. Proc. Natl. Acad. Sci. USA 2020, 117, 11648-11657. [CrossRef] [PubMed]

52. Fathi, Y.; Faghih, S.; Zibaeenezhad, M.J.; Tabatabaei, S.H.R. Kefir Drink Leads to a Similar Weight Loss, Compared with Milk, in a Dairy-Rich Non-Energy-Restricted Diet in Overweight or Obese Premenopausal Women: A Randomized Controlled Trial. Eur. J. Nutr. 2016, 55, 295-304. [CrossRef] [PubMed]

53. Blachier, F.; Beaumont, M.; Andriamihaja, M.; Davila, A.-M.; Lan, A.; Grauso, M.; Armand, L.; Benamouzig, R.; Tomé, D. Changes in the Luminal Environment of the Colonic Epithelial Cells and Physiopathological Consequences. Am. J. Pathol. 2017, 187, 476-486. [CrossRef] [PubMed]

54. Arboleya, S.; Watkins, C.; Stanton, C.; Ross, R.P. Gut Bifidobacteria Populations in Human Health and Aging. Front. Microbiol. 2016, 7, 1204. [CrossRef]

55. Ventura, M.; Turroni, F.; Lugli, G.A.; van Sinderen, D. Bifidobacteria and Humans: Our Special Friends, from Ecological to Genomics Perspectives. J. Sci. Food Agric. 2014, 94, 163-168. [CrossRef]

56. Hevia, A.; Milani, C.; López, P.; Donado, C.D.; Cuervo, A.; González, S.; Suárez, A.; Turroni, F.; Gueimonde, M.; Ventura, M.; et al. Allergic Patients with Long-Term Asthma Display Low Levels of Bifidobacterium Adolescentis. PLoS ONE 2016, 11, e0147809. [CrossRef]

57. Belenguer, A.; Duncan, S.H.; Calder, A.G.; Holtrop, G.; Louis, P.; Lobley, G.E.; Flint, H.J. Two Routes of Metabolic Cross-Feeding between Bifidobacterium adolescentis and Butyrate-Producing Anaerobes from the Human Gut. Appl. Environ. Microbiol. 2006, 72, 3593-3599. [CrossRef]

58. Thak, E.J.; Kim, J.; Lee, D.-J.; Kim, J.Y.; Kang, H.A. Structural Analysis of N-/O-Glycans Assembled on Proteins in Yeasts. J. Microbiol. 2018, 56, 11-23. [CrossRef]

59. Gemmill, T.R.; Trimble, R.B. Overview of N- and O-Linked Oligosaccharide Structures Found in Various Yeast Species. Biochim. Biophys. Acta (BBA)—Gen. Subj. 1999, 1426, 227-237. [CrossRef]

60. Bellikci-Koyu, E.; Sarer-Yurekli, B.P.; Akyon, Y.; Aydin-Kose, F.; Karagozlu, C.; Ozgen, A.G.; Brinkmann, A.; Nitsche, A.; Ergunay, K.; Yilmaz, E.; et al. Effects of Regular Kefir Consumption on Gut Microbiota in Patients with Metabolic Syndrome: A Parallel-Group, Randomized, Controlled Study. Nutrients 2019, 11, 2089. [CrossRef]

61. Bahroudi, S.; Shabanpour, B.; Combie, J.; Shabani, A.; Salimi, M. Levan Exerts Health Benefit Effect through Alteration in Bifidobacteria Population. Iran. Biomed. J. 2020, 24, 54-59. [CrossRef]

62. Hundschell, C.S.; Braun, A.; Wefers, D.; Vogel, R.F.; Jakob, F. Size-Dependent Variability in Flow and Viscoelastic Behavior of Levan Produced by Gluconobacter Albidus TMW 2.1191. Foods 2020, 9, 192. [CrossRef]

63. Jiao, N.; Baker, S.S.; Nugent, C.A.; Tsompana, M.; Cai, L.; Wang, Y.; Buck, M.J.; Genco, R.J.; Baker, R.D.; Zhu, R.; et al. Gut Microbiome May Contribute to Insulin Resistance and Systemic Inflammation in Obese Rodents: A Meta-Analysis. Physiol. Genom. 2018, 50, 244-254. [CrossRef]

64. De Almada, C.N.; Almada, C.N.; Martinez, R.C.R.; Sant'Ana, A.S. Paraprobiotics: Evidences on Their Ability to Modify Biological Responses, Inactivation Methods and Perspectives on Their Application in Foods. Trends Food Sci. Technol. 2016, 58 , 96-114. [CrossRef]

65. Liu, P.; Wang, Y.; Yang, G.; Zhang, Q.; Meng, L.; Xin, Y.; Jiang, X. The Role of Short-Chain Fatty Acids in Intestinal Barrier Function, Inflammation, Oxidative Stress, and Colonic Carcinogenesis. Pharmacol. Res. 2021, 165, 105420. [CrossRef]

66. Feng, Y.; Wang, Y.; Wang, P.; Huang, Y.; Wang, F. Short-Chain Fatty Acids Manifest Stimulative and Protective Effects on Intestinal Barrier Function through the Inhibition of NLRP3 Inflammasome and Autophagy. Cell. Physiol. Biochem. 2018, 49, 190-205. [CrossRef]

67. Paul, G.; Khare, V.; Gasche, C. Inflamed Gut Mucosa: Downstream of Interleukin-10. Eur. J. Clin. Investig. 2012, 42, 95-109. [CrossRef]

68. Mantovani, A.; Marchesi, F. IL-10 and Macrophages Orchestrate Gut Homeostasis. Immunity 2014, 40, 637-639. [CrossRef]

69. Foligné, B.; Dewulf, J.; Vandekerckove, P.; Pignède, G.; Pot, B. Probiotic Yeasts: Anti-Inflammatory Potential of Various NonPathogenic Strains in Experimental Colitis in Mice. World J. Gastroenterol. 2010, 16, 2134-2145. [CrossRef]

70. Wang, S.; Zhu, S.; Zhang, J.; Li, H.; Yang, D.; Huang, S.; Wei, Z.; Liang, X.; Wang, Z. Supplementation with Yeast Culture Improves the Integrity of Intestinal Tight Junction Proteins via NOD1/NF-кB P65 Pathway in Weaned Piglets and $\mathrm{H}_{2} \mathrm{O}_{2}-\mathrm{Challenged}$ IPEC-J2 Cells. J. Funct. Foods 2020, 72, 104058. [CrossRef]

71. Pasparakis, M. IKK/NF-KB Signaling in Intestinal Epithelial Cells Controls Immune Homeostasis in the Gut. Mucosal Immunol. 2008, 1, S54-S57. [CrossRef] [PubMed]

72. McEntee, C.P.; Finlay, C.M.; Lavelle, E.C. Divergent Roles for the IL-1 Family in Gastrointestinal Homeostasis and Inflammation. Front. Immunol. 2019, 10, 1266. [CrossRef] [PubMed] 